\title{
Analysis of a Nailed Soil Slope Using Limit Equilibrium and Finite Element Methods
}

\author{
S. Rawat $^{1}$ - A. K. Gupta ${ }^{1}$
}

Received: 5 September 2016/Accepted: 22 October 2016/Published online: 28 October 2016

(c) Springer International Publishing Switzerland 2016

\begin{abstract}
This paper aims at the two most common methods used for slope stability analysis. An attempt has been made to bring out the differences in results of reinforced slope stability analysis obtained from SLOPE/W (limit equilibrium based) and PLAXIS 2D (finite element based). The analysis is carried out on two slope angles of $45^{\circ}$ and $60^{\circ}$, which are reinforced with nails at three different inclinations of $0^{\circ}, 15^{\circ}$ and $30^{\circ}$ respectively. Both the slope angles and all nail inclinations are taken from the horizontal. A comparative study on stability parameters such as factor of safety, critical slip surfaces and nail forces has been carried out. The limit equilibrium method is found to yield higher values of factor of safety in comparison to finite element method. The failure surfaces from both methods are found to vary significantly. Large nail forces are observed by limit equilibrium method for $45^{\circ}$ slope with all nail inclinations, whereas for $60^{\circ}$ slope angle, finite element method shows an increase in the nail forces. The effect of other parameters like bond length in limit equilibrium, soil-nail interaction and bending stiffness in finite element are also studied.
\end{abstract}

Keywords Limit equilibrium - Finite element . Factor of safety $\cdot$ Slip surface $\cdot$ Nail forces

\footnotetext{
A. K. Gupta

ashok.gupta@juit.ac.in

S. Rawat

saurabh.rawat@juit.ac.in

1 Department of Civil Engineering, Jaypee University of Information Technology, Waknaghat, Solan, Himachal Pradesh 173234, India
}

\section{Introduction}

Soil nailing has emerged as an effective ground improvement technique especially in cases of slope instability. The unstable slopes can now be improved and made stable by the use of soil nailing technique. These reinforced slopes have to be analyzed for stability and their reinforcement methods. The stability analysis of reinforced slopes has been carried out by the traditional limit equilibrium approach by many researchers [1-4]. These limit equilibrium methods also known as the 'method of slices' is based on the concept of dividing the failure mass into slices, with certain assumptions on the interslice force distribution, for calculating the factor of safety. The assumptions are usually focused on inclination or location of the interslice forces and a pre-chosen slip surface of an assumed geometry like log-spiral, wedge and circular [5].

In addition to the limit equilibrium method (LEM), researchers have also employed the use of limit analysis which includes an upper bound approach and a lower bound approach. The lower bound approach $[6,7]$ incorporates static permissible stress fields in the analysis, which are usually assumed and do not hold any significant relations to the actual stress fields. Hence it is not easy to obtain the lower bound solutions for a practical slope problem. In the upper bound approach, the kinematically admissible velocity fields are constructed by a rigid element which makes the limit analysis of slope stability suitable for complex conditions such as slopes with complex geometries, profiles, groundwater conditions and complicated loadings [8-10]. However, rigid finite elements, linear finite elements, non linear programming or special sequential quadratic programming algorithm has also been used to obtain the optimal upper bound solution for structures and geotechnical problems [11]. 
The finite element method (FEM) [12] is also used to analyze the failure zone, soil non-linearity and the staged construction effect to predict the actual site conditions [13]. Numerical modelling of reinforced slopes by finite element method has proved very useful in prediction of slope deformation, stress analysis [14], nail pullout resistance $[15,16]$, nail forces along nail length, nail force variations with cohesion, angle of friction and lateral movement of slope [17-20]. The calculation of factor of safety using finite element is also possible by using the strength reduction method [21-23].

The strength reduction method (SRM) analysis is the reduction of strength parameters $(\phi$ and $c$ ) by factor of safety while the body forces due to weight of soil and other external loads are applied until system cannot maintain a stable condition [24]. This technique is also adopted in several well-known commercial geotechnical finite element or finite difference programs like PLAXIS 2D, SNAIL, ANSYS, FLAC 2D [25]. The strength reduction approach has also been used to solve pseudostatic stability problems in a frictional-cohesive material [26]. Gurocak et al. [27] have applied strength reduction method in rock slope stability analysis using two-dimensional (2D) finite element program. Although 2D analysis provides valuable insight into the behaviour of nailed slopes, the effect of soil-nail interaction is not adequately considered.

Recently, other method like the artificial neural networks (ANN) has also been developed to study the deformation of soil nailed walls [28]. The factor of safety calculation is now carried by measuring the strains using Fiber Bragg grating (FBG) sensing technology [29]. Esmaili [30] used close range photogrammetry for displacement measurement of soil nail walls. The global stability and sliding stability of soil nail walls against ultimate limit states are also evaluated using reliability analysis based on Monte Carlo simulation technique [31]. Reinforced slope stability analysis is also done by using statistical methods, adaptive neuro fuzzy inference system (ANFIS) and distinct element analysis method (DEM) [32].

This paper is an attempt to bring out the possible differences between the two most commonly used slope stability methods (LEM and FEM) in analysing the response of soil nailed slopes using software packages SLOPE/W and PLAXIS 2D v8.1. The numerical modelling of experimental work carried out by Rawat and Gupta [18] on nailed soil slope at different slope angles of $45^{\circ}$ and $60^{\circ}$ using nail inclinations of $0^{\circ}, 15^{\circ}$ and $30^{\circ}$ with the horizontal has been done. The comparison of factor of safety, failure slip surfaces and nail forces from LEM and FEM are studied and validated by the experimental results from Rawat and Gupta [18].

\section{Reinforced Slope Stability Analysis Using Limit Equilibrium Method}

The response of reinforced systems is primarily governed by the soil structure interaction. The interaction between the soil which provides both mobilized and resisting stresses and the structural members (nails) that helps in the load transfer mechanism. General limit equilibrium approach ensures static equilibrium of the system, thereby providing a global factor of safety for the ultimate limit state [5]. The factor of safety calculation as obtained by the general limit equilibrium (GLE) or just limit equilibrium (LE) method incorporates the use of interslice shear-normal forces and two types of factor of safety [33].

(a) Factor of safety with respect to moment equilibrium $\left(F_{m}\right)$

$F_{m}=\frac{\sum\left(c^{\prime} \beta R+(N-u \beta) R \tan \phi^{\prime}\right)}{\sum W x-\sum N f \pm \sum D d}$

(b) Factor of safety with respect to force equilibrium $\left(F_{f}\right)$

$F_{f}=\frac{\sum\left(c^{\prime} \beta \cos \alpha+(N-u \beta) \tan \phi^{\prime} \cos \alpha\right)}{\sum N \sin \alpha-\sum D \cos \omega}$

The normal force at the base of each slice $(N)$ is the major variable in both equations of factor of safety. The value of this normal force is dependent on the shear forces $\left(X_{L}\right.$ and $\left.X_{R}\right)$ acting on the slices as shown in Fig. 1.

The base normal force is obtained by the relation:

$N=\frac{W+\left(X_{R}-X_{L}\right)-\left(\frac{c^{\prime} \beta \sin \alpha+u \beta \sin \alpha \tan \emptyset^{\prime}}{F}\right)}{\cos \alpha+\frac{\sin \alpha \tan \emptyset^{\prime}}{F}}$

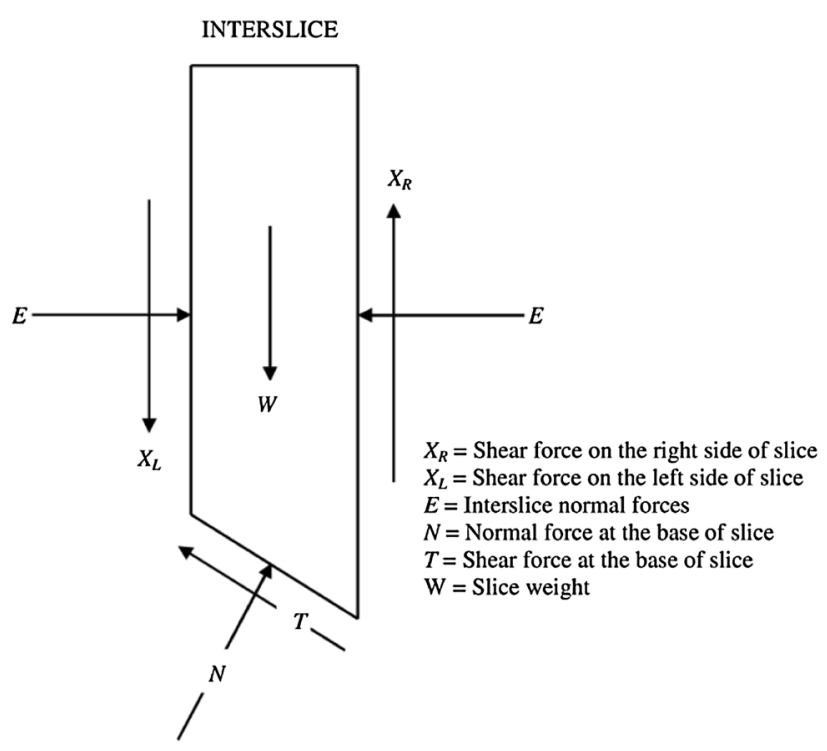

Fig. 1 Forces acting on an interslice 
where, $c^{\prime}$ and $\phi^{\prime}=$ effective cohesion and effective angle of friction $u=$ pore water pressure $W, D$ and $N=$ slice weight, concentrated point load and slice base normal force $\alpha=$ slice base inclination with the horizontal $\beta, f, d$, $\omega=$ geometric parameters.

The normal force calculated from Eq. (3) is used in the factor of safety calculation using Eqs. (1) and (2) for each slice for a range of $\lambda$ values. The $\lambda$ value is the difference between the specified function $f(x)$ used to relate the normal-shear forces on the slices and applied function $f(x)$ used by the LEM software [34]. The expression to find the relationship between the shear and normal forces on a slice is also given by Morgenstern and Price in 1965 as:

$\mathrm{X}=\mathrm{E} \cdot f(x) \cdot \lambda$

where, $X=$ interslice shear force $E=$ interslice normal force $f(x)=$ interslice function (half-sine function default SLOPE/W) $\lambda=$ percentage of function used.

The factor of safety using both the condition of moment and force is calculated until convergence is reached between the two FOS. The values are found to converge, when the FOS plot for moment and force intersect for a specific value of $\lambda$. This constitutes the global factor of safety as achieved by the LEM analysis of slopes.

The stability analysis in LEM is primarily an indeterministic problem. So, inorder to change the problem to statically deterministic solution, number of unknowns must be equal to the number of equations. Various assumptions such as no interslice forces (Fellinius method), no interslice shear forces (Bishop's method), only horizontal force equilibrium of wedge (Janbu's method) are accounted to achieve a factor of safety for the slope failure. However an additional complexity is introduced into the analysis with the use of reinforcement to stabilize the slope. The reinforcement parameters are prescribed, which do not introduce any unknowns in the analysis, but contributes additional known reinforcement forces that are included in the appropriate equilibrium equations [35]. The LEM method utilizes the trial slip surface method, inorder to locate the most optimum slip surface having the lowest factor of safety. The slip surfaces considered in the LEM can be circular, piece-wise linear or a combination of curved and linear shapes. The procedure to find the most critical slip surface is also affected by stratigraphic boundaries of the slopes. To avoid unrealistic slip surface and factor of safety, the LEM package offers an option of defining the regions for occurrence of slip surface on the ground surface and point of axis along which the moment equilibrium is to be calculated. The present study uses the software package SLOPE/W, to analyse the reinforced slope by LEM.

\section{Modelling and Analysis Using SLOPE/W}

SLOPE/W is a sub-routine of the software package GEOSLOPE. In the present study, reinforced soil slope are modelled with two different slope angles of $45^{\circ}$ and $60^{\circ}$ with horizontal respectively. These soil slopes are reinforced using nails at three different nail inclinations from horizontal of $0^{\circ}, 15^{\circ}$ and $30^{\circ}$ respectively [36]. SLOPE/W package enables construction of the soil slopes by defining its regions. The dimensions of the soil slope have been adopted from the experimental work done on nailed soil slopes [18]. The dimensions of the slope model used for experimental studies are scaled down and incorporated in SLOPE/W, by using a scale of $1 \mathrm{~cm}=0.5 \mathrm{~m}$.

The slope is modelled at different slope angles by $(x$, $y$ ) coordinate system available in the package. Material of the slope is assigned, once the slope regions have been determined. The slopes are then reinforced with the help of nails. SLOPE/W package provides the option of using reinforcement in the form of anchor, geosynthetic, nail and pile. For the present study reinforcement of slopes has been done using nail element. A surcharge load is applied at the top of slope, which is also scaled down from the experimental values [18]. The entry and exit of slip surfaces at the ground surface along with the slip surface axis and limits are also applied at the model. The simulated model used in the analysis is shown in Fig. 2. Amidst of all other methods available in the limit equilibrium package, the analysis is carried out by Morgenstern-Price method which uses a relation between interslice shear forces and inters slice normal forces. The interslice function selected in the analysis is a half-sine function with a constant factor of safety distribution calculation. The soil and nail properties used in the model are summarized in Table 1.

The nails used in reinforcing of the slopes are simulated without a facing in the form of 'no anchorage' of nails at the slope face. The nail forces are treated as distributed forces over the nail length and the overall global factor of safety ( $\mathrm{F}$ of $\mathrm{S}$ dependent) is included in the analysis. The reinforcement in SLOPE/W is treated as concentrated loads which reduces the destabilizing forces. The equilibrium equations used in the analysis are based on the shear mobilized at the base of each slice and at the reinforcement. The mobilized shear $\left(S_{m}\right)$ is calculated using the Eq. (5), based on an assumption that the shear resistance of soil and reinforcement are developed at the same rate [5].

$S_{m}=\frac{S_{\text {soil }}}{F \text { of } S}+\frac{S_{\text {reinforcement }}}{F \text { of } S}$

The soil nails used in the analysis are stiffer than the soil. Hence the reinforcement forces are limited by the 
Fig. 2 Modelling of soil slope in SLOPE/W

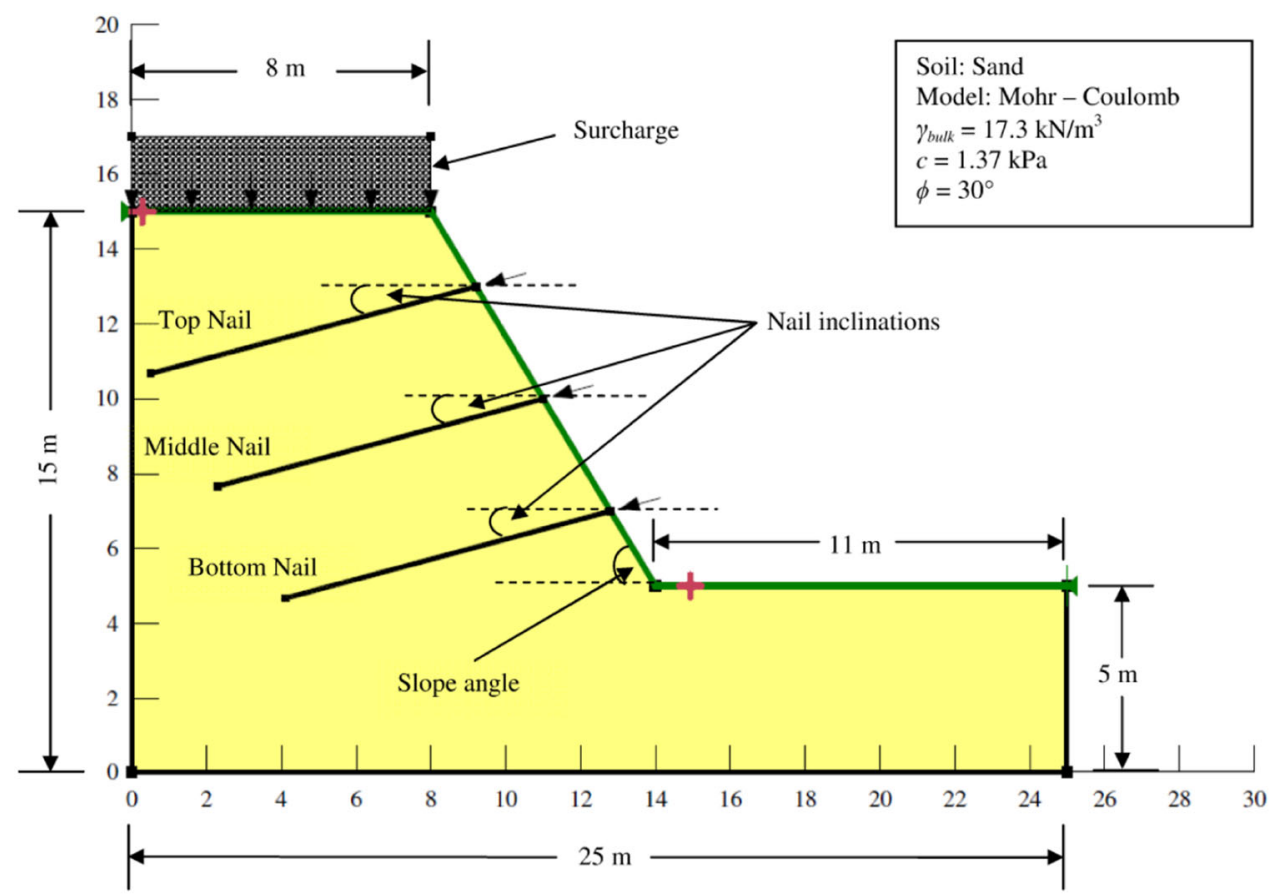

Table 1 Summary of material used in modelling from Rawat and Gupta [18]

\begin{tabular}{ll}
\hline Parameters & Values \\
\hline Soil & Well graded sand $(\mathrm{SW})$ \\
Bulk unit weight of soil $\left(\gamma_{\text {bulk }}\right)$ & $17.3 \mathrm{kN} / \mathrm{m}^{3}$ \\
Cohesion $(c)$ & $1.37 \mathrm{kN} / \mathrm{m}^{2}$ \\
Angle of friction $\left(\phi^{\circ}\right)$ & $30^{\circ}$ \\
Surcharge load & $0.294 \mathrm{kN} / \mathrm{m}^{3}$ \\
Pull-out resistance of nails & $100 \mathrm{kN} / \mathrm{m}^{2}$ \\
Tensile capacity of nails & $200 \mathrm{kN}$ \\
Nail spacing $(s)$ & $2 \mathrm{~m}$ \\
Length of nail $(l)$ & $7.5 \mathrm{~m}$ \\
\hline
\end{tabular}

allowable loads in the reinforcement. Instead of dividing the shear resistance of reinforcements with global factor of safety, reduction factors are used to restrict the mobilized reinforcements. This option is available by not considering the F of $\mathrm{S}$ dependency for the analysis.

\section{SLOPE/W Results from Limit Equilibrium Analysis}

\section{Factor of Safety from SLOPE/W}

From Table 2, it is observed that the factor of safety calculated from the limit equilibrium method is found to be 1.82 for a slope of $45^{\circ}$ with nail inclination of $15^{\circ}$. Similarly for a slope of $60^{\circ}$, the highest factor of safety of 1.53
Table 2 Factor of safety from limit equilibrium method (SLOPE/W)

\begin{tabular}{llll}
\hline $\begin{array}{l}\text { Slope angles with } \\
\text { horizontal }\left(^{\circ}\right)\end{array}$ & \multicolumn{2}{l}{ Factor of safety } \\
\cline { 2 - 4 } & \multicolumn{2}{l}{ Nail inclinations with horizontal } \\
\cline { 2 - 3 } & $0^{\circ}$ & $15^{\circ}$ & $30^{\circ}$ \\
\hline 45 & 1.69 & 1.82 & 1.20 \\
60 & 1.50 & 1.53 & 1.10 \\
\hline
\end{tabular}

is found for nail inclination of $15^{\circ}$. The factor of safety as can be observed from Table 2 is found to increase from nail inclination of $0^{\circ}$ to $15^{\circ}$ and then decrease from $15^{\circ}$ to $30^{\circ}$. This pattern is observed for both the slope angle of $45^{\circ}$ and $60^{\circ}$. The Morgenstern-Price method employed by SLOPE/W utilizes a $\lambda$ value to check for the convergence of the results. As shown in Fig. 3a, b, the FOS values attained for nail inclinations of $15^{\circ}$ in $45^{\circ}$ and $60^{\circ}$ slopes are found to satisfy the convergence of results. The FOS as obtained is the intersection of FOS from moment equilibrium $\left(F_{m}\right)$ and FOS from force equilibrium $\left(F_{f}\right)$.

\section{Failure Slip Surface from SLOPE/W}

From the Fig. 4a, b and c, it can be seen that a circular slip surface is generated for reinforced slopes of $45^{\circ}$. It is also observed from the figures that the slip surface is passing through the entire crest in cases with nail inclination of $0^{\circ}$ and $15^{\circ}$. However, with nail inclination of $30^{\circ}$, a much smaller slip surface is observed. The red shaded portion of the slip surface indicates the band of trial slip surfaces with the same factor of safety. 
(a)

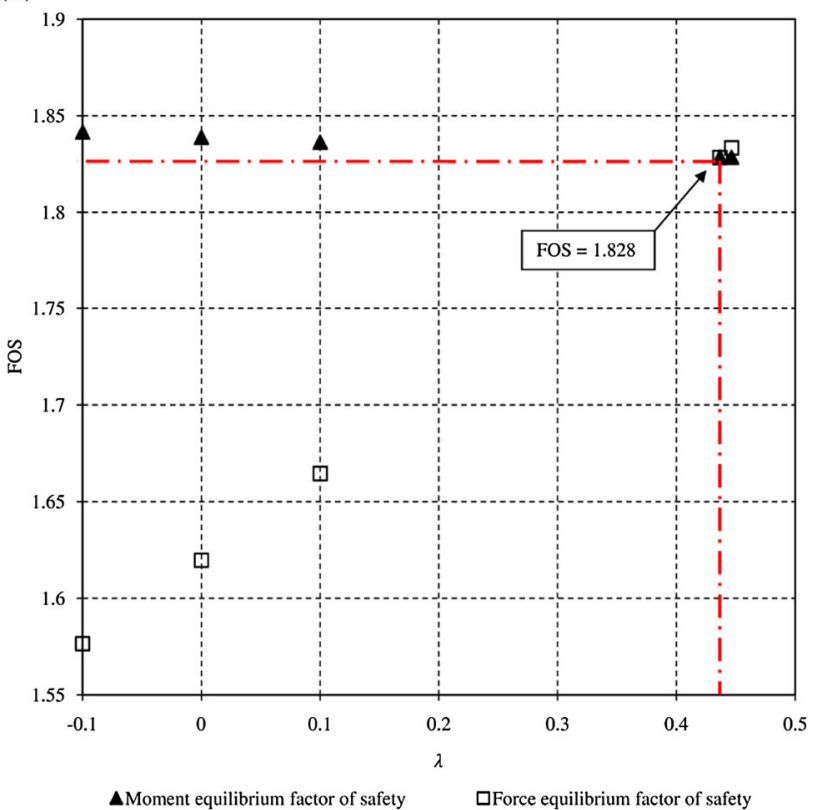

(b)

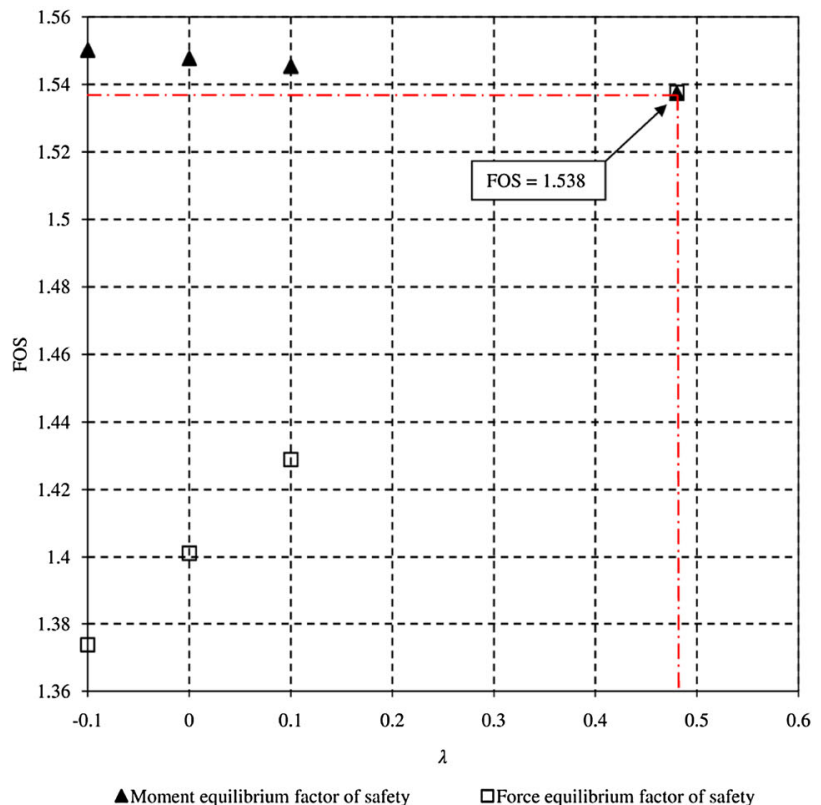

Fig. 3 a FOS versus $\lambda$ for $45^{\circ}$ slope with nail inclination of $15^{\circ}$. b FOS versus $\lambda$ for $60^{\circ}$ slope with nail inclination of $15^{\circ}$

For the $60^{\circ}$ slope, it can be seen from the Fig. 5a, b, c that the slip surface is circular in shape. For slopes with nail inclination of $0^{\circ}$ and $15^{\circ}$, the variation in the factor of safety for the trial surface is small. This is indicated by thin red shaded portion of the slip surface. However, $60^{\circ}$ slope reinforced with $30^{\circ}$ nail inclination is found to have a small slip failure and critical slip surface is found to lie close to the slope face.

\section{Nail Axial Forces from SLOPE/W}

From the Fig. 6a, b, it is observed that the bottom nail with $0^{\circ}, 15^{\circ}$ and $30^{\circ}$ is found to bear the maximum nail axial forces for both $45^{\circ}$ and $60^{\circ}$ slopes. For nail inclinations of $0^{\circ}$ and $15^{\circ}$, the axial forces are found to increase from top nail to middle nail and maximum for the bottom nails. However, for $30^{\circ}$ inclined nail $45^{\circ}$ slope, an axial force of $100 \mathrm{kN}$ is found in the top, middle and bottom nails. Similarly, an axial force of $66.66 \mathrm{kN}$ is found for top, middle and bottom nails in $60^{\circ}$ slope with $30^{\circ}$ nail inclination. The maximum axial force of $100 \mathrm{kN}$ is found to be in the bottom nail for $45^{\circ}$ slope with nail inclination at $30^{\circ}$. In $60^{\circ}$ slope, the bottom nail with nail inclination of $0^{\circ}$ is found to bear the maximum axial nail force of $71.67 \mathrm{kN}$.

\section{Effect of Bond Length from SLOPE/W}

From the analysis carried out in SLOPE/W, it is found that the length of nails modelled and mobilized during slip failure vary with the nail inclination and location. The nails at all the inclinations of $0^{\circ}, 15^{\circ}$ and $30^{\circ}$ are initially modelled with a constant length of $7 \mathrm{~m}$ converted to scale. The SLOPE/W analysis yields that the nail inclination of $30^{\circ}$ in both the slope angles, enables less than $50 \%$ of nail length mobilization to resist slope failure. For the other two nail inclinations $0^{\circ}$ and $15^{\circ}$, it is found that more than $90 \%$ of the nail length has been used to resist the shearing action. It is found that if the failure surface uses maximum nail length, the reinforcing action of the nails is completely mobilized. The summary of the percentage mobilized nail length is given in Table 3. The LE analysis of the reinforced slope also accounts for the fact that load transfer mechanism of nails is governed by pull-out resistance or tensile capacity of nails. It is visible from Fig. $4 a, b$, that $45^{\circ}$ slope with $0^{\circ}$ and $15^{\circ}$ nail inclinations do not depict any nail breakage. This signifies that the load transfer mechanism is governed by nail pullout capacity.

For $30^{\circ}$ nail inclination on $45^{\circ}$ slope, nails are found to break denoted by dashed lines (Fig. 7). This also stands for the fact that nail has completely utilized its pullout capacity and is now transferring the load by its tensile capacity. A similar pattern of nail load transfer mechanism is observed in $60^{\circ}$ reinforced slope with $30^{\circ}$ nail inclination as shown in Fig. 8.

\section{Reinforced Slope Stability Analysis Using Finite Element Method}

With the advantage of no assumption for location of failure surface and interslice forces, finite element (FE) method has been widely accepted for the analysis of slope stability 
(a)

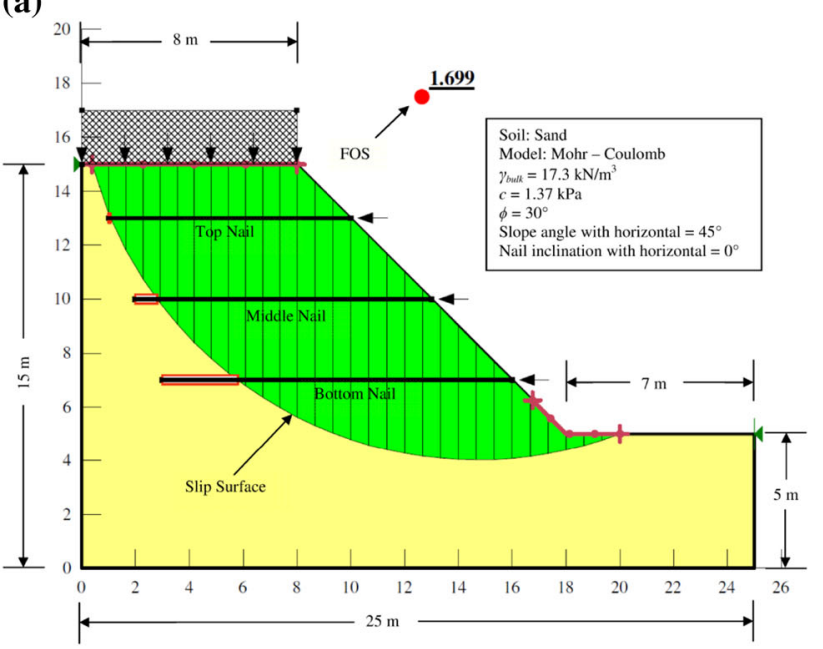

(b)

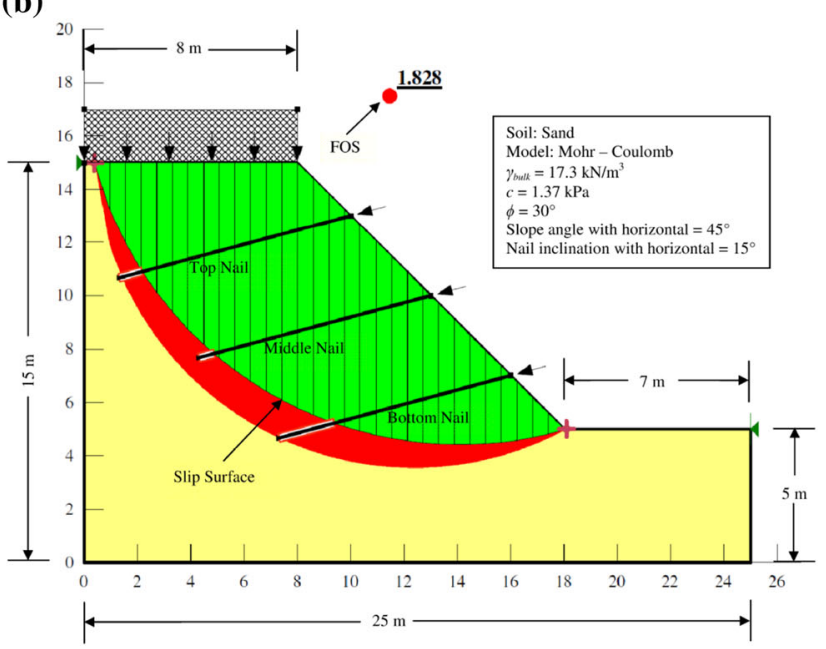

(c)

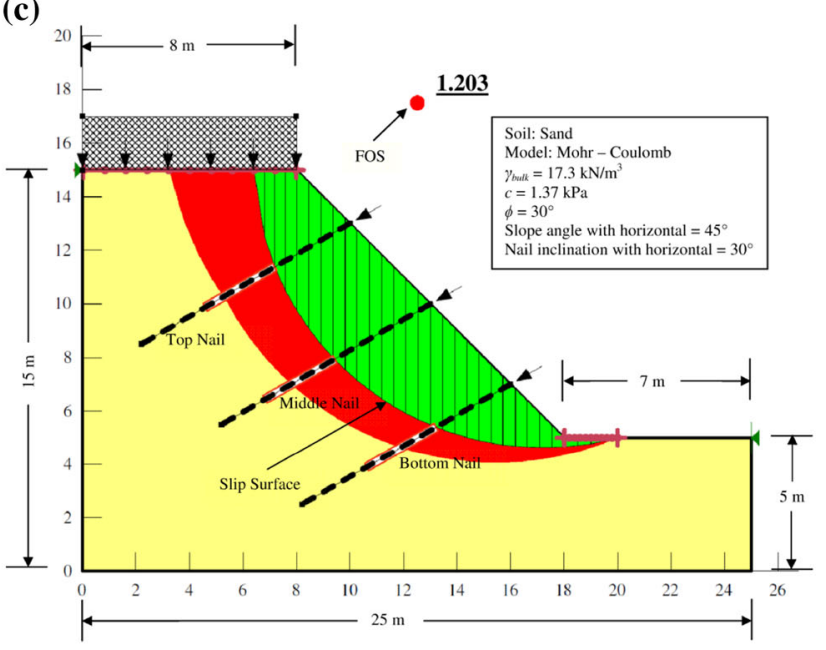

Fig. 4 a Slip Surface for $45^{\circ}$ slope for $0^{\circ}$ nail inclination. b Slip Surface for $45^{\circ}$ slope for $15^{\circ}$ nail inclination. c Slip Surface for $45^{\circ}$ slope for $30^{\circ}$ nail inclination. (Color figure online)

[12]. The increased use of complex geometries and material data has made analysis non-linear and iterative in nature. In such cases the inputs (soil and geometry) are themselves function of the solutions. Since this procedure requires a large amount of calculation data and time, it is recommended to use available FE packages. One such FE software package has been used in the current study named as PLAXIS 2D v8.1. In this software, FE analysis divides the continuum into distinct elements, with each element further divided into nodes. The unknowns in the problem with a defined set of boundary conditions correspond to degree of freedom with discrete values for each node [13]. In the present work, degree of freedom of the nodes is related to displacement components. Each line element is divided into three nodes which are assigned displacement values. These three nodes contribute to the six noded triangles, whereas if the line element has five nodes, it builds up a 15-noded triangle. The 15-noded triangles are found to yield more accurate results as compared to six noded, in cases involving nails, anchors or geogrids [13].

The material in the FE analysis is also controlled by the infinitesimal incremental stress and strain relationship. The FEM package incorporates the use of Mohr-Coulomb constitutive model. This routine simulates a perfectly plastic material condition with development of irreversible strains. A set of yield functions which constitute a yield surface are generated to check the occurrence of plastic points in the continuum. These yield functions are themselves a function of prevailing stress and strain conditions. The FEM routine also enables to simulate an elastic perfectly plastic behaviour of the material. Hooke's law is used to relate the stress to the strains. These strains and the strain rates are decomposed into their elastic and plastic fraction during calculations. Smith and Griffith [37] stated that the Mohr-Coulomb model consists of six yield functions which consist of plastic parameters like ' $c$ ' and ' $\phi$ ' of 
(a)

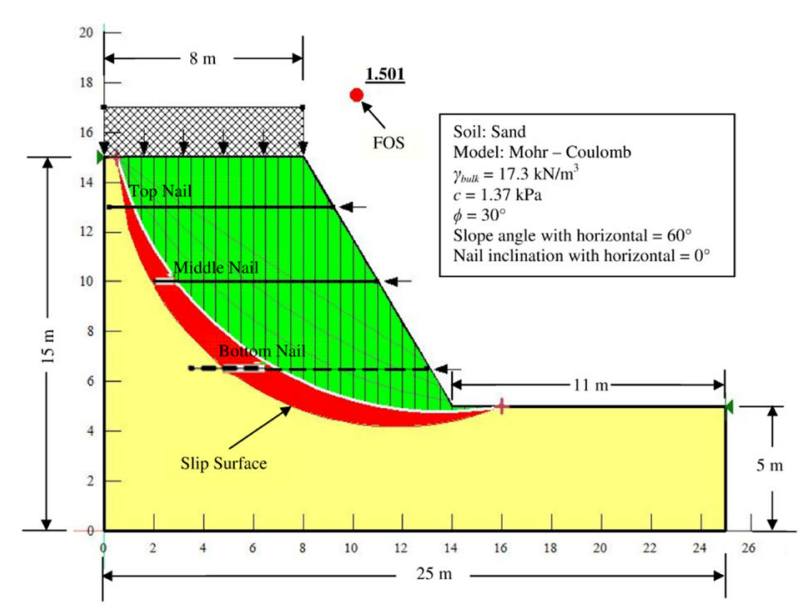

(b)

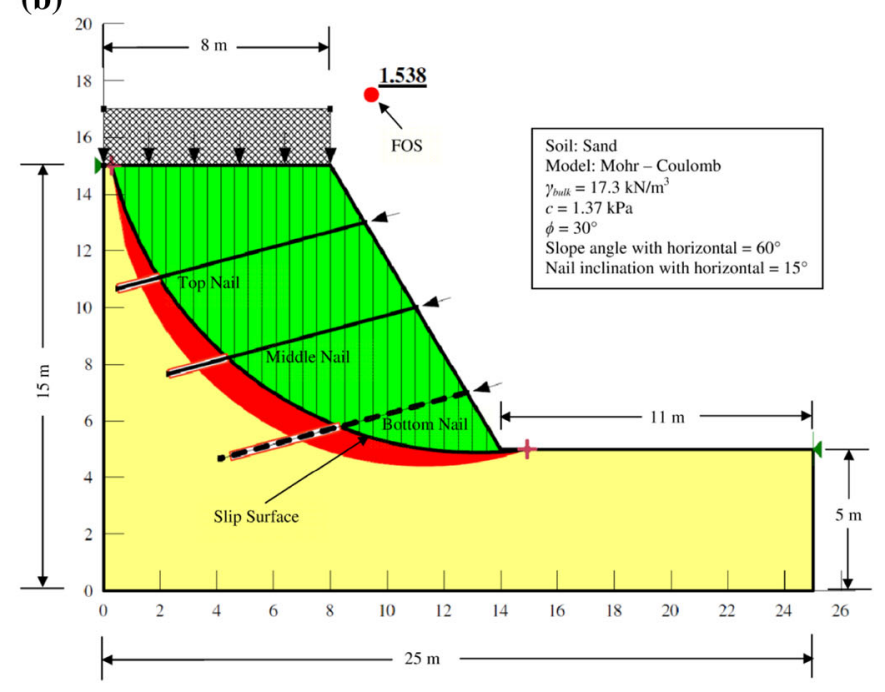

(c)

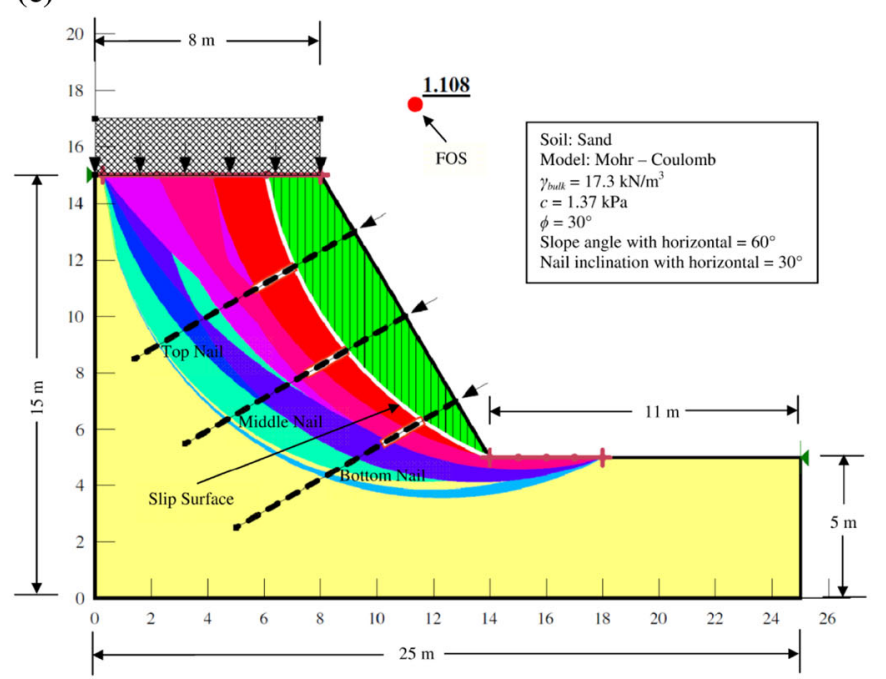

Fig. 5 a Slip Surface for $60^{\circ}$ slope for $0^{\circ}$ nail inclination. b Slip Surface for $60^{\circ}$ slope for $15^{\circ}$ nail inclination. c Slip Surface for $60^{\circ}$ slope for $30^{\circ}$ nail inclination. (Color figure online)

the soil. Using these concepts for material transition, a material stiffness matrix is developed by the FE analysis to calculate the stiffness of each element and ultimately of the entire volume of soil.

From the literature review, it has also been observed that researchers [38, 39] employed the strength reduction method of FE to obtain the factor of safety for slopes. In strength reduction analysis, the convergence criterion is the most critical factor for the assessment of factor of safety. The strength reduction method also known as $\phi-c$ reduction method is carried out by performing load advancement number of steps. The reduction in the strength parameters in carried out by using an incremental multiplier $M_{s f}$. The factor of safety is calculated by the expression:
$S F=\frac{\text { Available strength }}{\text { strength at failure }}=$ value of $\sum M_{s f}$ at failure.

The precision of the factor safety is a function of type of constitutive soil model selected, type and size of the element, discretized mesh, node location for displacement curve and tolerance allowed for non-linear analysis. Depending on the choice of the FE routine used, the model is found to have reached the ultimate state if either the maximum number of iteration is reached or the model has undergone a continuous failure mechanism or the selected points in the continuum are subjected to sudden change in the displacement. Inorder to simulate the failure correctly FEM packages also provide the 
(a)

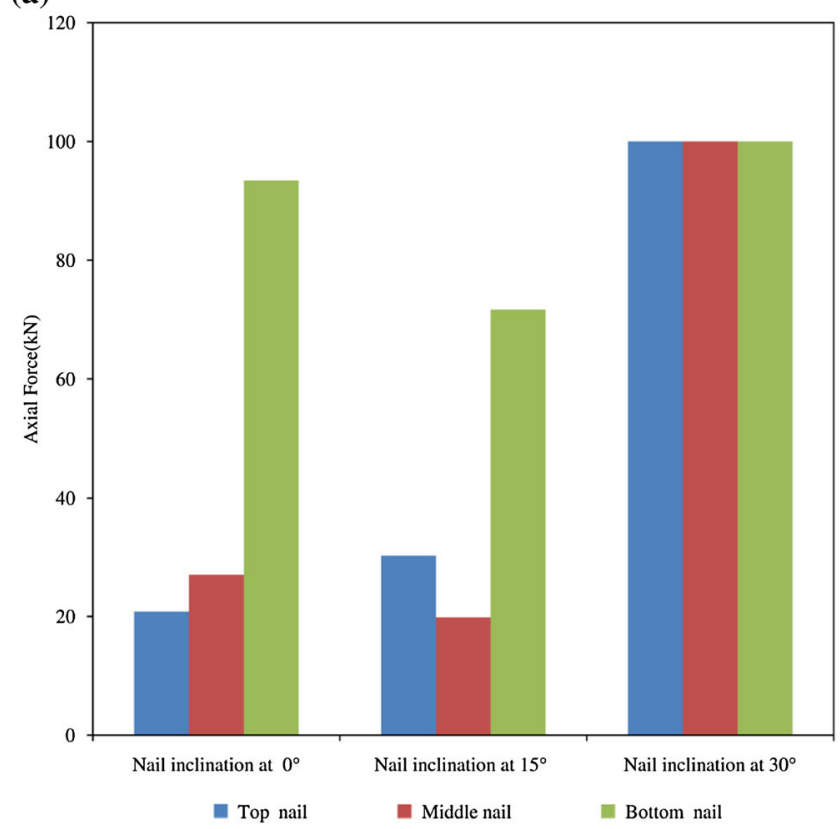

(b)

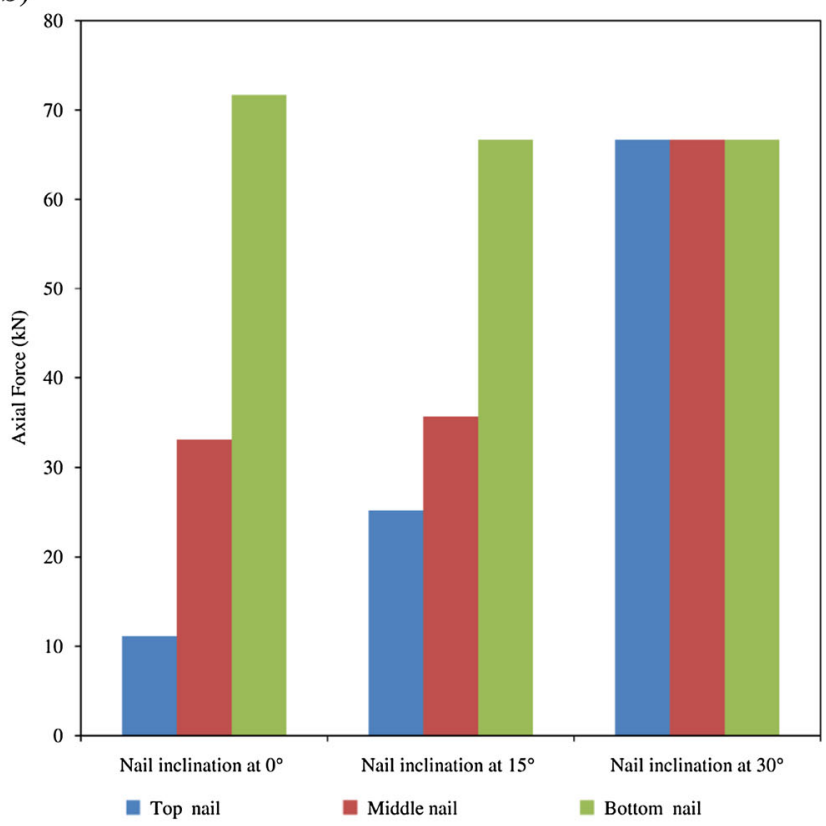

Fig. 6 a Axial force distribution in top, middle and bottom nails with different nail inclinations for $45^{\circ}$ slope. b Axial force distribution in top, middle and bottom nails with different nail inclinations for $60^{\circ}$ slope. (Color figure online)

Table 3 Summary of the nail length mobilized

\begin{tabular}{lllll}
\hline $\begin{array}{l}\text { Slope angles } \\
\text { with horizontal }\left(^{\circ}\right)\end{array}$ & $\begin{array}{l}\text { Nail inclinations } \\
\text { with horizontal }\left(^{\circ}\right)\end{array}$ & \multicolumn{3}{l}{$\%$ age nail length used } \\
\cline { 3 - 5 } & & Top nail & Middle nail & Bottom nail \\
\hline 45 & 0 & 99.73 & 98.80 & 93.60 \\
& 15 & 91.20 & 90.80 & 87.33 \\
60 & 30 & 45.07 & 48.67 & 42.80 \\
& 0 & 98.27 & 94.80 & 89.73 \\
& 15 & 87.47 & 85.20 & 77.33 \\
& 30 & 30.80 & 27.47 & 24.67 \\
\hline
\end{tabular}

use of arc-length control in iteration procedure. At times during a non-linear analysis, a sudden failure of some points is observed which lead to the generation of an "apparent" negative stiffness matrix beyond the ultimate limit state. This snap through problem in FEM has been overcome by the arclength control technique. The arc-length control technique is now incorporated in the commercial finite element software PLAXIS to obtain reliable collapse loads for load controlled calculations. Hence PLAXIS 2D based on finite element method accompanied with an elastic perfectly plastic (Mohr-Coulomb) stress-strain relation is used in this study, which is reliable and powerful approach for calculating the factor of safety of slopes.

\section{Numerical Modelling and Analysis Using PLAXIS 2D}

The numerical modelling of reinforced slopes has been carried out by FE routine PLAXIS 2D v8.1. PLAXIS 2D considers the soil slope in plain strain with 15-noded triangulation procedure. The dimensions of the model are similar to the dimensions adopted in LE analysis. The standard fixities are used to simulate the actual boundary conditions of the model test conducted by Rawat and Gupta [18]. The base of the model is restricted in the $\mathrm{x}-\mathrm{y}$ direction with the back of the slope being restricted only in the $\mathrm{x}$-direction by using the standard fixities. A Mohr-Coulomb model with well graded sand soil is used to simulate the model in FEM. A drained soil condition is considered with the phreatic line positioned at the base of the model. The parameters used in the modelling of slope and nails are summarized in Table 4. The PLAXIS package provides the option of using plate element, geogrids, node to node anchors and fixed end anchors to be used as reinforcement systems. However an elastic equivalent plate element can be used as nails for slope reinforcement. As observed from the literature review [40-42] the bending stiffness and the axial stiffness play an important role in the simulation of the nails. If the nails are modelled using a plate 
Fig. 7 Slope stability by tensile capacity of nails in $45^{\circ}$ slope with $30^{\circ}$ nail inclination. (Color figure online)

Fig. 8 Slope stability by tensile capacity of nails in $60^{\circ}$ slope with $30^{\circ}$ nail inclination. (Color figure online)
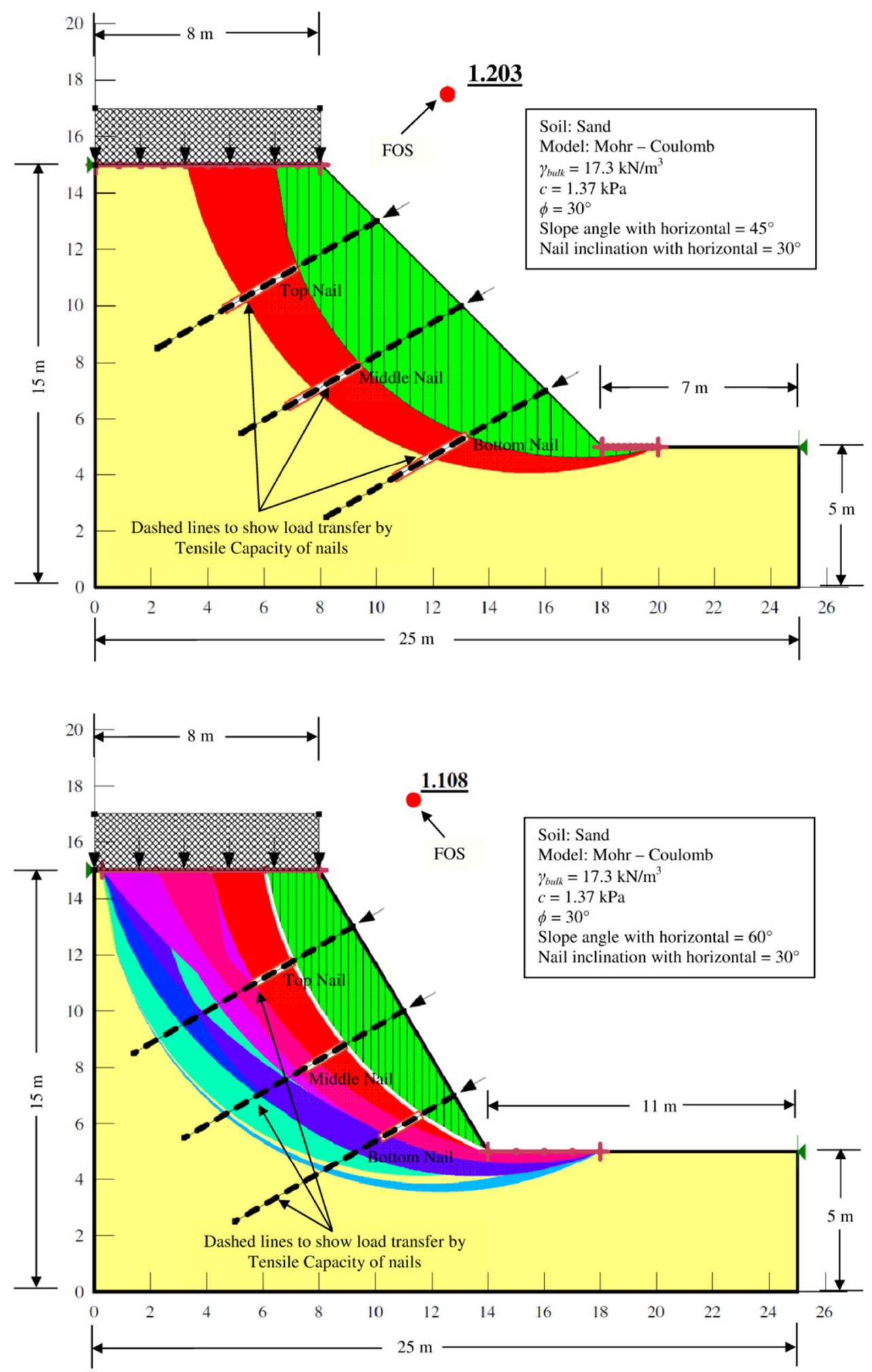

element of circular cross section, then an equivalent flexural rigidity and equivalent axial stiffness has to be calculated for correct simulation of the soil nails. The formulation for attaining the equivalent modulus of elasticity for the modelled nails is given by Babu et al. [43]:
$E_{\text {eq }}=E_{n} \frac{A_{\text {nail }}}{A}+E_{g} \frac{A_{\text {grout }}}{A}$

Similarly Equivalent axial stiffness is given by 
Table 4 Material properties used in numerical modelling from Rawat and Gupta [18]

\begin{tabular}{llllllll}
\hline Properties & \multicolumn{3}{l}{ Stiffness } & \multicolumn{2}{l}{ Alternate stiffness } & \multicolumn{2}{l}{ Strength } \\
\hline Simulated model & Plain strain & $E_{\text {ref }}$ & $50,000 \mathrm{kN} / \mathrm{m}^{2}$ & $G_{\text {ref }}$ & $115,400 \mathrm{kN} / \mathrm{m}^{2}$ & $c_{\text {ref }}$ & $1.37 \mathrm{kN} / \mathrm{m}^{2}$ \\
Elements & 15 -node & 0 & 0.3 & $E_{\text {oed }}$ & $403,800 \mathrm{kN} / \mathrm{m}^{2}$ & $\phi$ & $30^{\circ}$ \\
Model type & Mohr-Coulomb & & & & & $\psi$ & $0^{\circ}$ \\
Material type & Drained & & & & & & \\
$\gamma_{\text {unsat }}$ & $13.6 \mathrm{kN} / \mathrm{m}^{3}$ & & & & & & \\
$\gamma_{\text {sat }}$ & $19.68 \mathrm{kN} / \mathrm{m}^{3}$ & & & & & & \\
$K_{o}$ & 0.5 & & & & & & \\
\hline
\end{tabular}

$E A=\frac{E_{n}}{S_{h}} \frac{\Pi}{4} d_{n}^{2}$

The equivalent bending stiffness is calculated by the relation:

$E I=\frac{E_{n}}{S_{h}} \frac{\Pi}{64} d_{n}^{4}$

The equivalent plate diameter of the nail is calculated by the PLAXIS software using the formulation:

$d_{e q}=\sqrt{12\left(\frac{E I}{E A}\right)}$

The Eqs. (7), (8), (9) and (10) are used in the present study to calculate the nail input values used for the analysis as shown in Table 5.

To ensure proper soil-nail interaction, an interface of virtual thickness factor $(\delta)$ of 0.1 is used. This virtual thickness factor is multiplied by the element thickness in the procedure of mesh generation. The interface is assigned the same material data set as done for the model. For simulation of pullout resistance in the soil nails, an interface strength reduction factor $\left(R_{\text {inter }}\right)$ is used with a value of $2 / 3$ in the absence of data from experimentation [13]. It relates the strength of the soil to the strength of interface as

$\frac{\tan \phi_{\text {interface }}}{\tan \phi_{\text {soil }}}=R_{\text {inter }}$ and $\frac{c_{\text {interface }}}{c_{\text {soil }}}=R_{\text {inter }}$

Once the soil nail interactions are modelled, a 2D mesh is generated after the initial stresses are computed by the $K_{0}$ procedure based on Janbu's relation, $K_{0}=(1-\sin \phi)$. A finer $2 \mathrm{D}$ mesh is generated at the interfaces of soil-nail for achieving accurate results. No overconsolidation and pre- overburden pressure are considered in the present analysis. The simulated model is analysed by using the $\phi-c$ reduction method (SRM). This calculation method yields a value of incremental multiplier $\sum M_{s f}$ as results converge when slope failure is reached. This value of the incremental multiplier is treated as FOS for the reinforced slope failure. The complete modelled reinforced soil slope is shown in the Fig. 9.

\section{PLAXIS 2D Results from Finite Element Method}

\section{Factor of Safety from PLAXIS 2D}

The PLAXIS $2 \mathrm{D}$ shows that $45^{\circ}$ slope reinforced with nail inclination of $15^{\circ}$, yields the maximum factor of safety of 1.43. For all the other inclinations of $0^{\circ}$ and $30^{\circ}$, the factor of safety is found to be 1.36 and 1.15 respectively. As it can be seen from Fig. 10 , for $15^{\circ}$ nail inclination the factor of safety is increasing with slope displacement under surcharge lis achieved for a total displacement (IUI) of $0.462 \mathrm{~m}$ of slope. It can also be observed from Figs. 10 and 11 that $30^{\circ}$ nail inclination in both $45^{\circ}$ and $60^{\circ}$ slope gives the minimum factor of safety of 1.15 and 1.08 respectively. Figure 10 also suggests that nail inclinations with minimum factor of safety fail at a relative smaller displacement as compared to the nail inclinations giving the maximum FOS. The nail inclination of $0^{\circ}$ corresponds to an intermediate factor of safety value 1.36 for $45^{\circ}$ slope and 1.17 for $60^{\circ}$ slope respectively. Another important aspect that can be brought to light is that for $60^{\circ}$ slope, the factor of safety increasing rapidly at small displacement of $<0.1 \mathrm{~m}$ and then remains constant until failure as the slope
Table 5 Properties of the simulated nails used in numerical modelling

\begin{tabular}{lllll}
\hline Parameters & Values & Units & \multicolumn{2}{l}{ Interface strength } \\
\hline Nail element and nail type & Plate and elastic & - & $R_{\text {inter }}$ & $2 / 3$ \\
Axial stiffness $(E A)$ & $2.98 \times 10^{6}$ & $\mathrm{kN} / \mathrm{m}$ & $\delta_{\text {inter }}$ & 0.1 \\
Flexural rigidity $(E I)$ & $113.64 \times 10^{3}$ & $\mathrm{kN} \mathrm{m}{ }^{2} / \mathrm{m}$ & \\
Diameter of nail $\left(d_{e q}\right)$ & 12 & $\mathrm{~mm}$ & \\
Poisson's ratio $(v)$ & 0.35 & - & \\
\hline
\end{tabular}


Fig. 9 Numerical modelling of reinforced soil slope in PLAXIS 2D

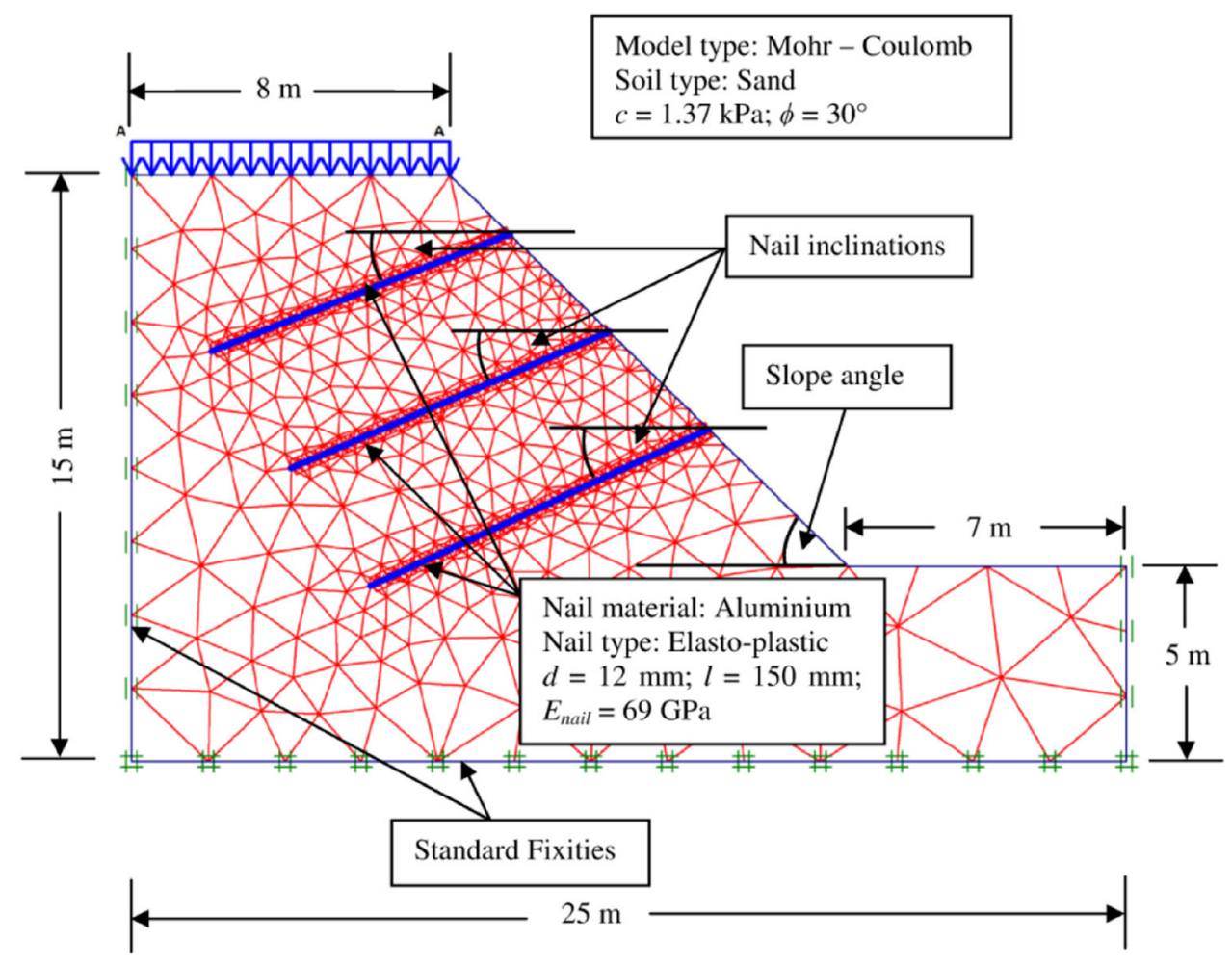

Fig. 10 Factor of safety against slope displacement from PLAXIS 2D for different nail inclinations at $45^{\circ}$ slope. (Color figure online)

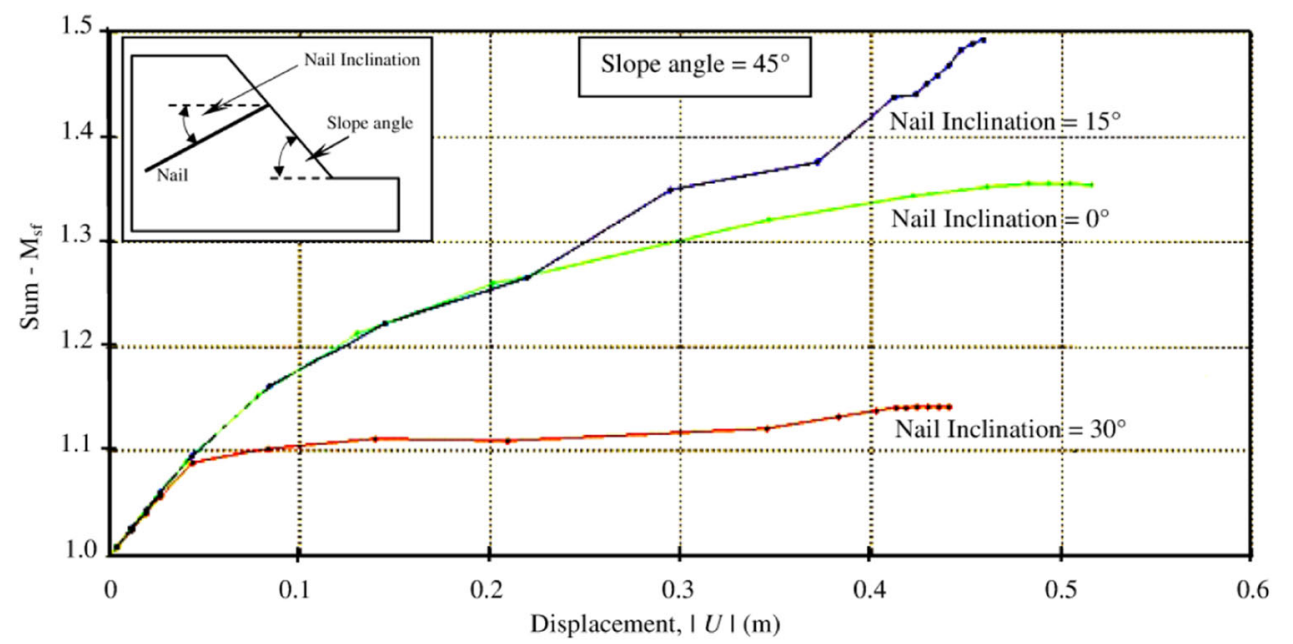

displacement increases. The maximum factor of safety for $60^{\circ}$ is 1.37 achieved for $15^{\circ}$ nail inclination. Similar to $45^{\circ}$ slope, $0^{\circ}$ and $30^{\circ}$ show much lower values of factor of safety. Nail inclination of $30^{\circ}$ is found to have the minimum factor of safety for $60^{\circ}$ slope which is concurrent to slope angle of $45^{\circ}$.

\section{Slip Surface from PLAXIS 2D}

From the analysis of reinforced slopes by FEM routine PLAXIS, it is observed that different slopes with varying nail inclination undergo non-circular slip surface failure. Although these slip surfaces are found to vary with change in nail inclination. Figure 12a depicts that FEM analysis gives a slip surface passing in close proximity to the slope face in case of nail inclined at $0^{\circ}$ for $45^{\circ}$ slope. A similar pattern of non circular slip surfaces is attained from failure of $45^{\circ}$ slope with $15^{\circ}$ and $30^{\circ}$ nail inclinations. It can also be observed from Fig. $12 \mathrm{~b}, \mathrm{c}$ that unlike $0^{\circ}$ nail inclination, slip surfaces pass through the nails with $15^{\circ}$ and $30^{\circ}$ nail inclinations. However in all three nail inclinations, the maximum horizontal displacement is found to be near the reinforced slope face.

The failure of $60^{\circ}$ slope shows a different failure pattern in comparison to $45^{\circ}$ slopes. As observed from Fig. 13a, it can be seen that for $0^{\circ}$ nail inclination in $60^{\circ}$ slope 
Fig. 11 Factor of safety against slope displacement from PLAXIS 2D for different nail inclinations at $60^{\circ}$ slope. (Color figure online)

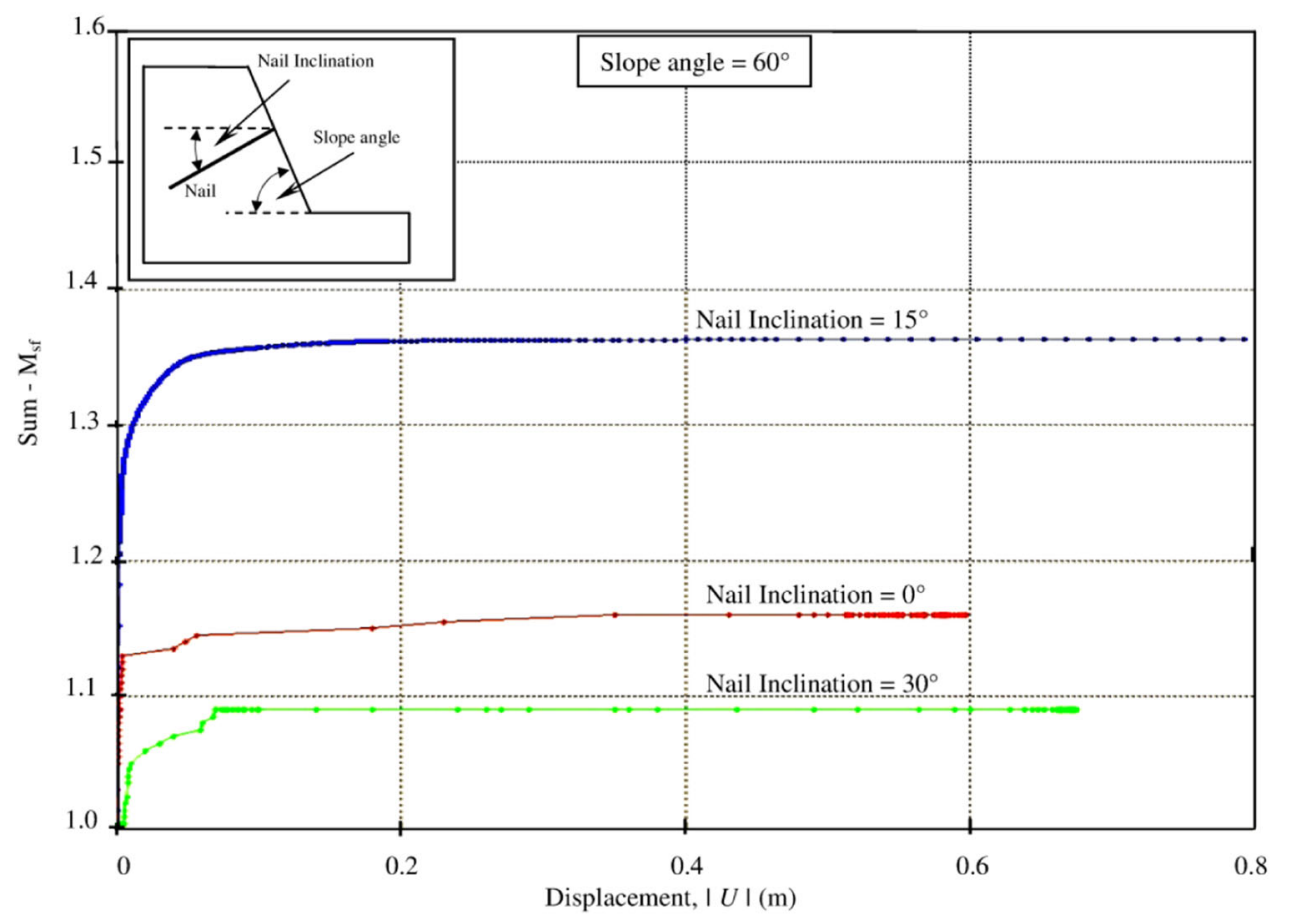

undergoes a non circular slip surface. This slip surface failure is more similar to the sliding failure. However the entire crest is found to have displaced under the surcharge loading. For nail inclinations of $15^{\circ}$, a much defined slip surface is obtained from the analysis. The slip surface originates from slope crest and terminates at toe. It can be defined as a non circular and non linear type of slip surface failure. The slip surface can also be observed to have intersected the nails during failure (Fig. 13b).

A complex failure pattern is observed from Fig. 13c for $60^{\circ}$ slope with nail inclinations of $30^{\circ}$. The slope failure pattern is observed in contrast to toe failures obtained for $0^{\circ}$ and $15^{\circ}$ nail inclinations. The slip surface is a wedge failure occurring primarily on the upper portion of the slope face. It can also be seen that the larger portion of failure wedge do not even pass through the bottom nail. The slope is also found to have largely deformed as compared to other nail inclinations for slope angle of $60^{\circ}$.

\section{Axial Nail Forces from PLAXIS 2D}

The axial forces as calculated from FEM clearly shows that the maximum nail forces are found for nail inclination of $15^{\circ}$ for both $45^{\circ}$ and $60^{\circ}$ slopes. A maximum force of $59.34 \mathrm{kN}$ is found in bottom nail of $15^{\circ}$ nail inclination. The axial force in the bottom nail is found maximum among the three locations of nails namely top, middle and bottom nails. The nail inclination of $0^{\circ}$ has the maximum axial nail force at bottom nail of magnitude $53.06 \mathrm{kN}$ while an axial nail force of $25.39 \mathrm{kN}$ is found at the bottom nail of inclination $30^{\circ}$. The axial forces are also found to be more for nail inclination of $15^{\circ}$, followed by $0^{\circ}$ and having minimum value for nail inclination of $30^{\circ}$ in $45^{\circ}$ slope. The variation in the axial forces for $45^{\circ}$ slope with different nail location and inclination is given in Fig. 14.

The axial force distribution for $45^{\circ}$ slope angle is shown in Fig. 15. It can be observed that the pull out capacity and tensile capacity are generated as the failure is reached. The distribution of the nail force is found to increase from the nail end, reach a maximum value and then decreases towards the nail head. The maximum value of this nail force can be found for the bottom nail followed by the middle nail and minimum for the top nail. Similarly the nail force distribution for all the nail inclinations can be obtained from the analysis. In this paper however only the nail forces yielding the highest FOS are covered.

For slope $60^{\circ}$, the maximum axial force is found for the bottom nail at an inclination of $15^{\circ}$. The pattern of decrease in axial nail forces from bottom to top nail is also visible from Fig. 16 for all nail inclinations. The $15^{\circ}$ nail inclination is found to have a value of $208.08 \mathrm{kN}$ for bottom nail, $124.68 \mathrm{kN}$ for middle nail and $57.41 \mathrm{kN}$ for top most nail. The nail inclination of $30^{\circ}$ is found to yield the lowest values of axial nail forces for top, middle and bottom nails as $50.7,64.81$ and $65.42 \mathrm{kN}$ respectively.

The nail force distribution as shown in Fig. 17 further shows that a maximum tensile force is generated in the bottom nail of $15^{\circ}$ nail inclination in $60^{\circ}$ slope. It can be 
(a)

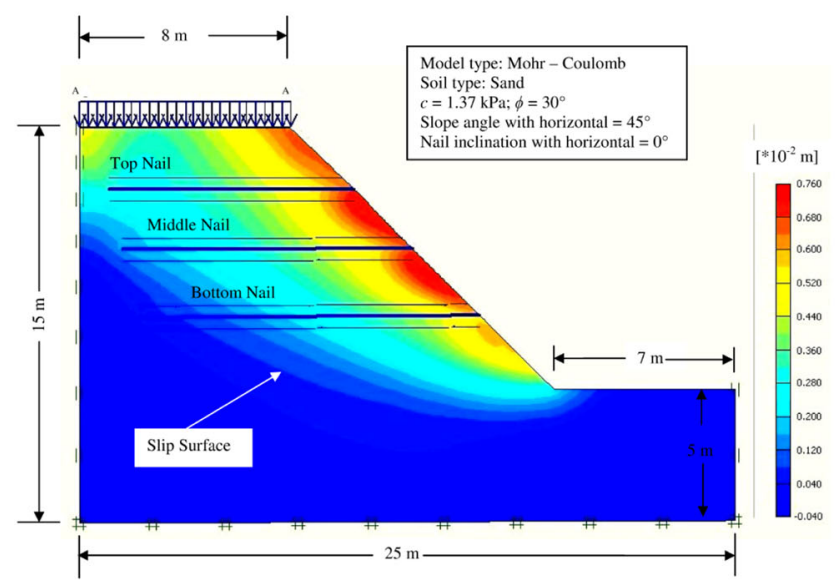

(b)

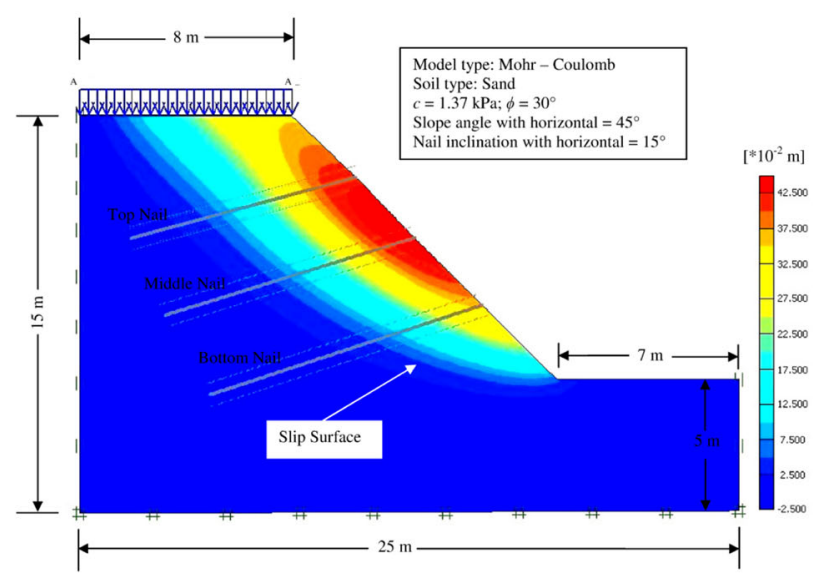

(c)

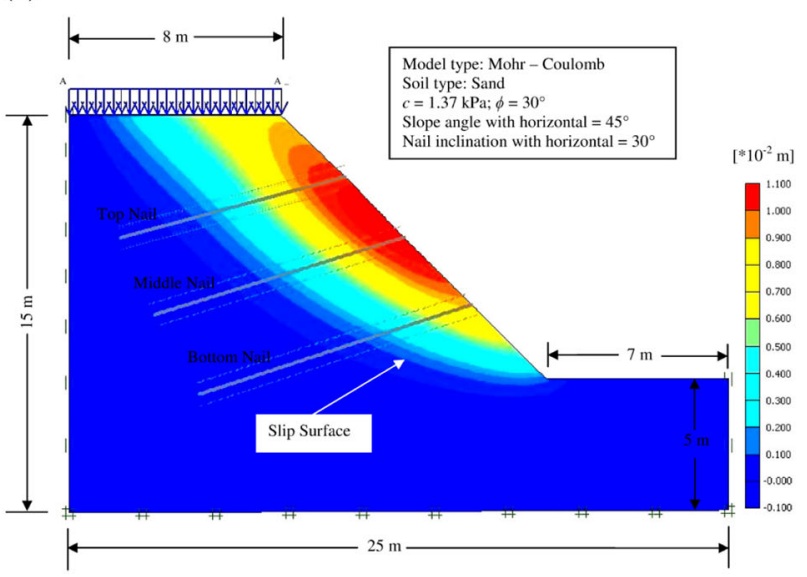

Fig. 12 a Slip Surface at failure for $45^{\circ}$ slope angle from PLAXIS with nail inclination of $0^{\circ}$. b Slip Surface at failure for $45^{\circ}$ slope angle from PLAXIS with nail inclination of $15^{\circ}$. c Slip Surface at failure for $45^{\circ}$ slope angle from PLAXIS with nail inclination of $30^{\circ}$. (Color figure online)

seen from nail force distribution curves that the top nail and middle nail have lower nail forces. A similar pattern of nail forced distribution is also observed in the $45^{\circ}$ slope with the same nail inclination.

The distribution of nail force as shown in Fig. 17 signifies that the bottom nail has the two limiting conditions of nail forces. The initial increase in the distribution shows that the nail has mobilized its full pullout capacity. After the pullout capacity has been used up, nail tensile capacity has governed the load transfer mechanism for the bottom nail. The top nail and the bottom nail are also found with a similar nail force distribution pattern, but it both the cases only the tensile capacity governs the nail forces. In the absence of facing for the nailed slopes used in this work, the nail force distribution is found to terminate at the nail head.

The shear force distribution curves are used to find the locus of maximum nail forces. The shear forces along nail length are found to change from positive to negative. This transition is found to occur at points of maximum tensile capacity of the respective nail. As seen from the Fig. 18a, $\mathrm{b}$, it is observed that locus of the maximum nail force and slope slip surface may lie at different distances from the slope face.

\section{Effect of Soil-Nail Interaction and Bending Stiffness of Nails from PLAXIS 2D}

In the absence of data for interface strength, trials have been carried out with different values of $R_{\text {inter }}$. The effect of soil nail interface on FOS can be found from Fig. 19. It is seen that an increase in FOS of about $1.39 \%$ is found for $45^{\circ}$ slope with $15^{\circ}$ nail. The $60^{\circ}$ slope with $15^{\circ}$ nail inclination is found to have an increase of $3.64 \%$ in FOS with variation of $R_{\text {inter }}$ from 0.6 (default) to 1.0 (max) value. During the analysis, it is also observed that FOS, slip surfaces, deformed mesh and nail forces are also found to vary with different bending stiffness and axial stiffness values incorporated in finite element analysis. 
(a)

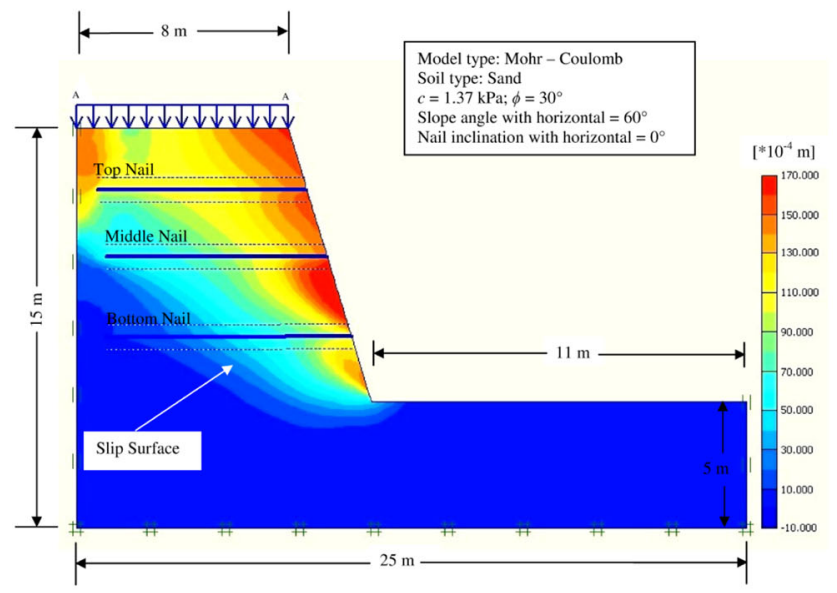

(b)

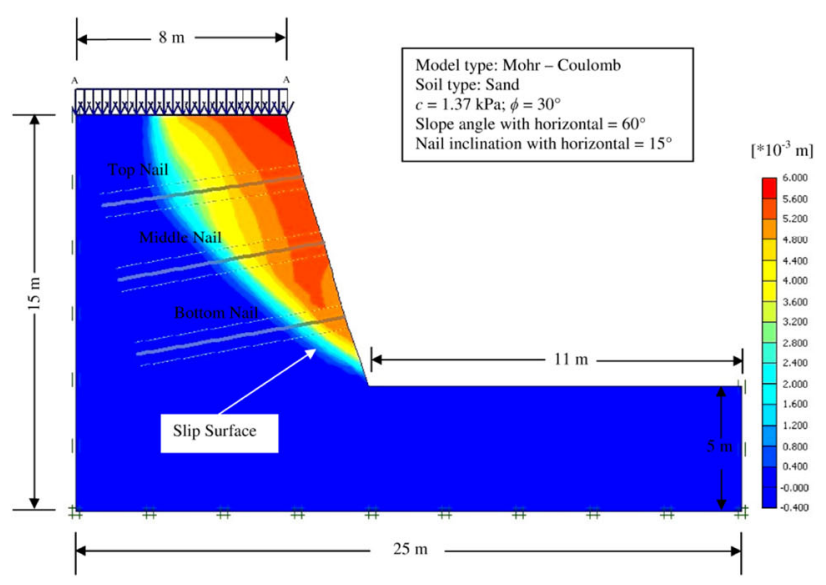

(c)

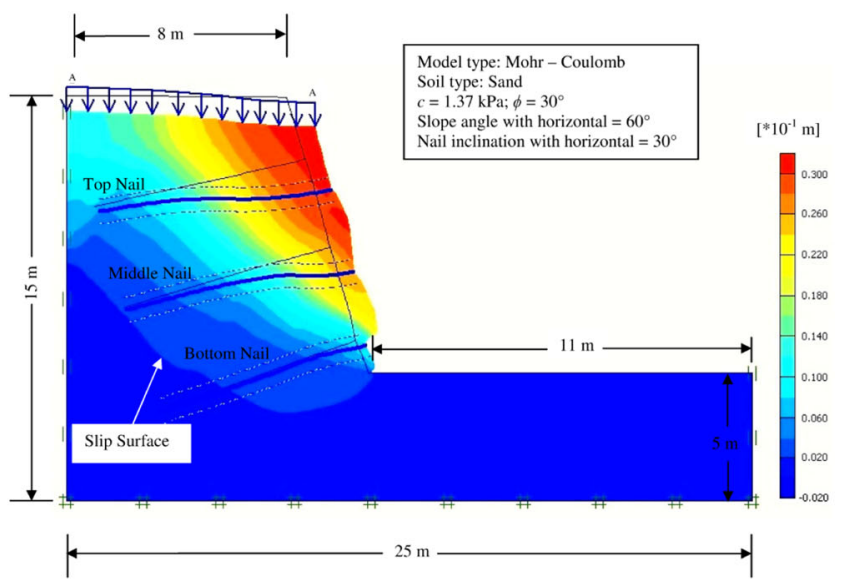

Fig. 13 a Slip Surface at failure for $60^{\circ}$ slope angle from PLAXIS with nail inclination of $0^{\circ}$. b Slip Surface at failure for $60^{\circ}$ slope angle from PLAXIS with nail inclination of $15^{\circ}$. $\mathrm{c}$ Slip Surface at failure for $60^{\circ}$ slope angle from PLAXIS with nail inclination of $30^{\circ}$. (Color figure online)

\section{Validation of Failure Surfaces}

A model testing and experimental validation has been incorporated for the present analysis. The laboratory model testing carried out on soil nailed slope by Rawat and Gupta [18] is used to validate the results as observed from LEM and FEM analysis in this paper. It can be observed from Fig. 20a, b, that the failure surface captured from LEM analysis (SLOPE/W) and FEM analysis (PLAXIS 2D) are comparable to the failure slip surface obtained from model testing with slight variations. The slip surface found from model testing is not necessarily a circular slip surface but a non-circular slip surface or a log spiral surface. The experimental results yield a shallow slip surface which is concentrated near the slope face. The slip surface is found to originate at the slope crest near the slope face. It propagates towards the toe. For reinforced slope of $45^{\circ}$, the slip surface intersects the slope face above the toe which can be categorized as a slope failure. Moreover, a much visible toe failure is found to occur for $60^{\circ}$ reinforced slope. The numerical modelling of this slope with LEM sub-routine SLOPE/W shows a rather circular slip surface at failure. Also it can be seen from Fig. 4a, b, c, that a deep failure surface is predicted by limit equilibrium analysis which is not the case from model testing. The slip surface by LEM is also found to pass well below the slope toe for $45^{\circ}$ reinforced slope, whereas a slope failure is obtained from model testing. In case of $60^{\circ}$ reinforced slope, both model testing and LEM analysis depicts toe failure with variation in slip surface depth. As mentioned earlier, LEM gives a deep slip surface which originates away from slope face and from the rear of slope crest, whereas the slip surface from model testing is also circular but slightly steeper as compared to LE analysis result. It can also be observed that the experimental slip surface starts somewhere from the crest and ends at the toe similar to LEM.

The slip surfaces obtained from PLAXIS 2D (FEM) analysis are found to give results which are in good 
Fig. 14 Axial nail forces at different nail inclinations and locations for $45^{\circ}$ slope. (Color figure online)

Fig. 15 Nail force distribution from PLAXIS 2D
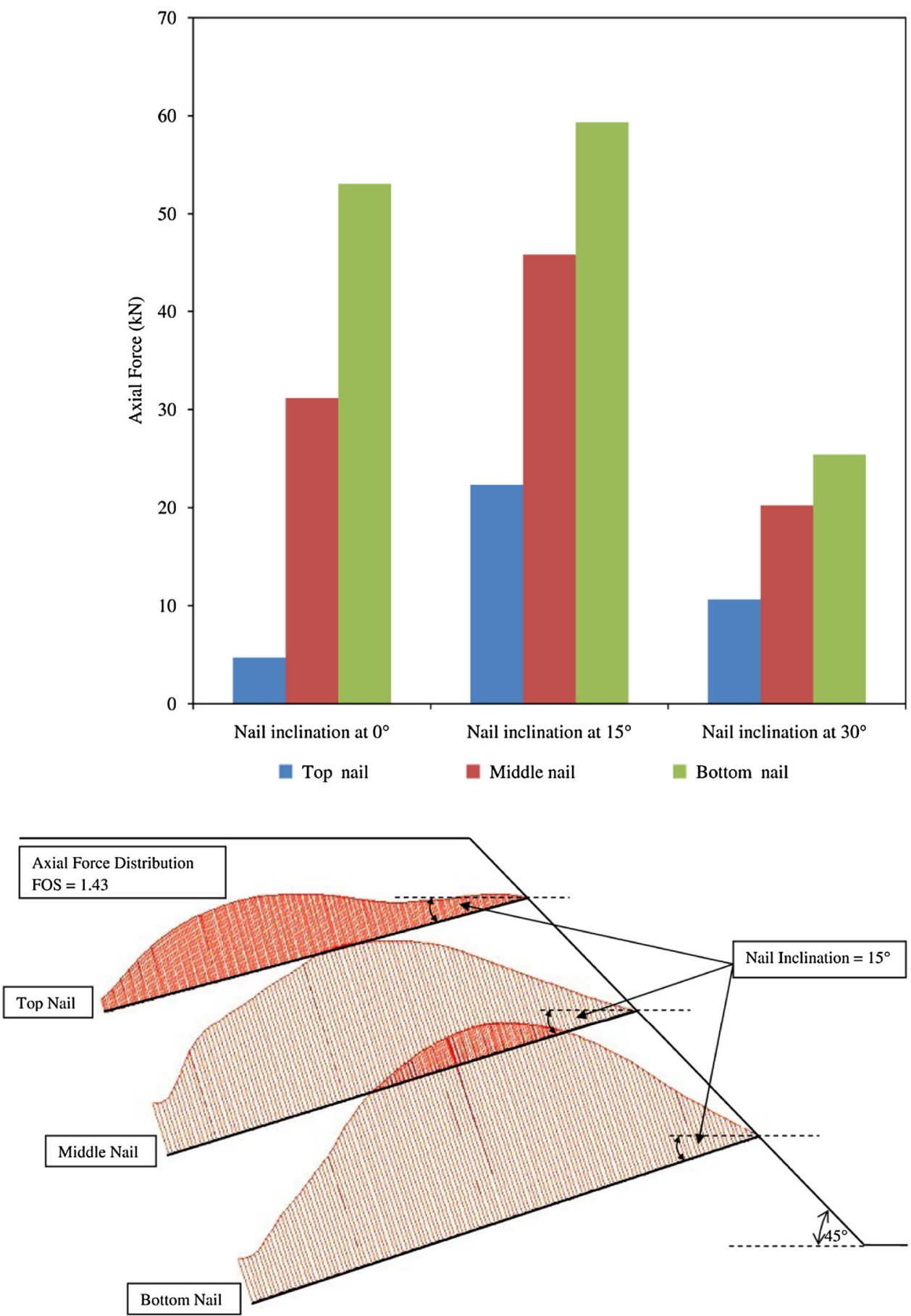

agreement with model testing slip surfaces. For $45^{\circ}$ reinforced slope, non-circular slip surface originating from slope crest slightly away from slope face is observed from both FEM analysis as well as experimentally. However, PLAXIS also gives a base failure in contrast to slope failure found by testing. From Figs. 12 a to $13 \mathrm{c}$, it can also be seen that the stresses are found to be concentrated near the slope face and decreases as distance from the slope face increases. The slip surface for $60^{\circ}$ reinforced slope obtained from FEM is similar to the experimental slip surface. Both slip surfaces are toe slope failure with noncircular shape of slip and lie close to the slope face.

Hence it can be said that FE analysis carried out by PLAXIS 2D gives more realistic failure surfaces as compared to LE analysis by SLOPE/W. However, both the analytical methods failed to predict the significant crest 
Fig. 16 Axial nail forces at different nail inclinations and locations for $60^{\circ}$ slope. (Color figure online)

Fig. 17 Nail force distribution from PLAXIS 2D
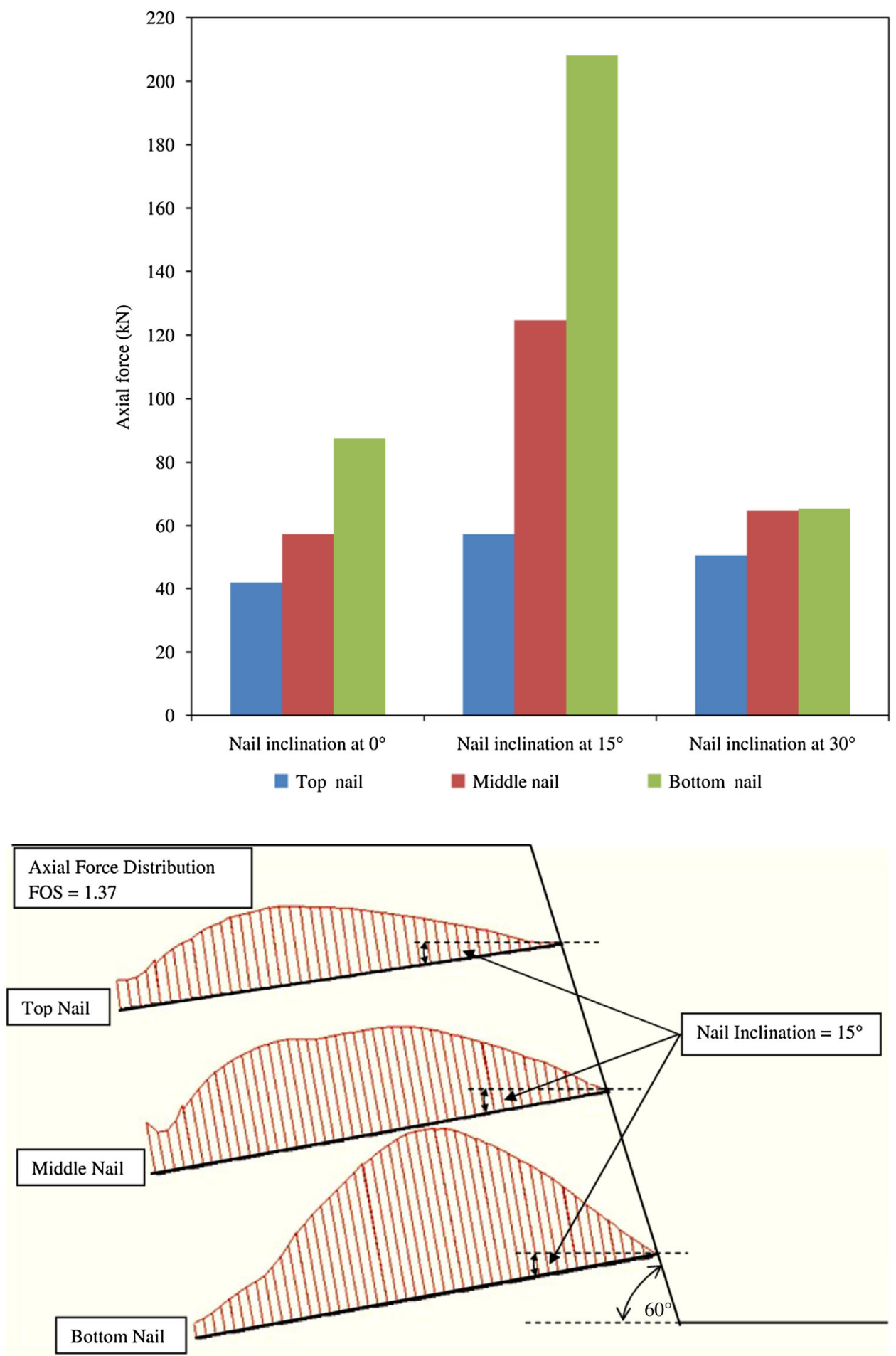

settlement which occurred in model testing. The variations between experimental work of Rawat and Gupta [18] and the current analytical methods can be accounted for the following reasons:

(a) LEM works on the concept of assumed failure surface (circular in this case) with lowest factor of safety in contrast to FEM where critical slip surface is generated by failure stress-strains on the displacement nodes. This makes FEM results more realistic than LEM results.

(b) The boundary conditions modeled in LEM and FEM are different from model testing. SLOPE/W does not 
Fig. 18 a Shear force distribution of $15^{\circ}$ nail inclination for $45^{\circ}$ slope. b Shear force distribution of $15^{\circ}$ nail inclination for $60^{\circ}$ slope

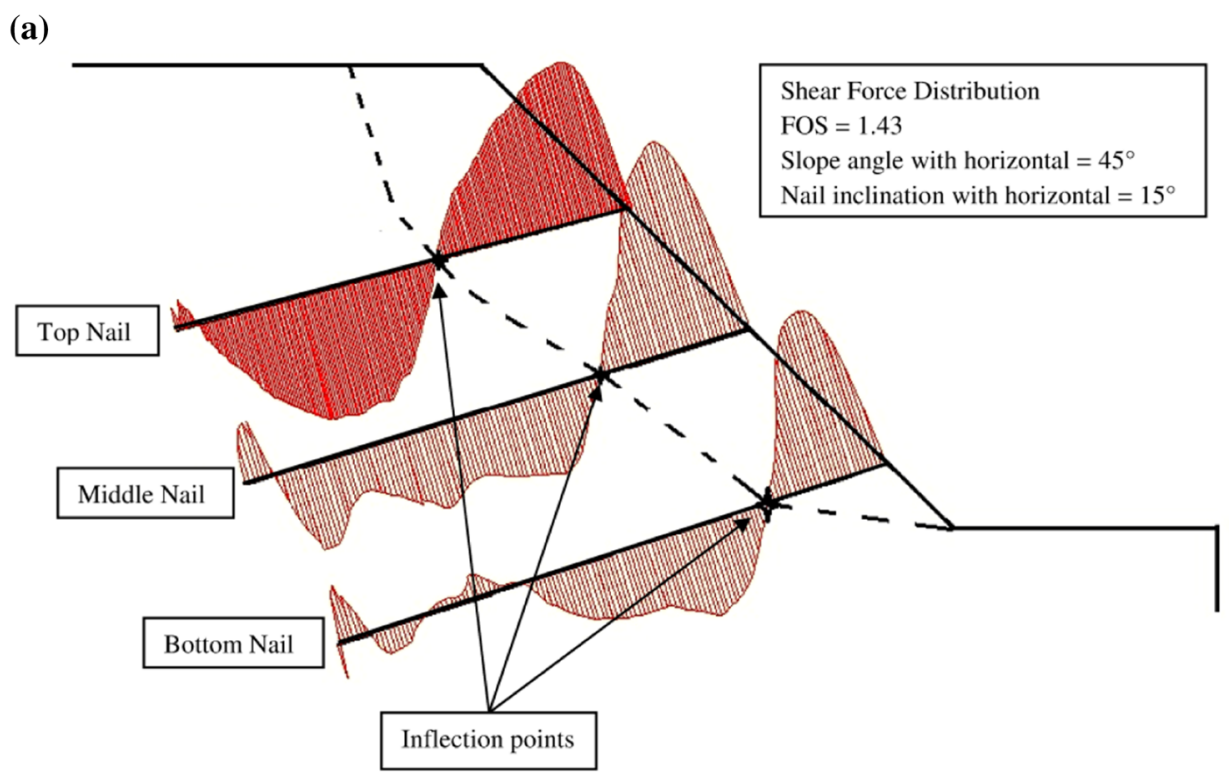

(b)

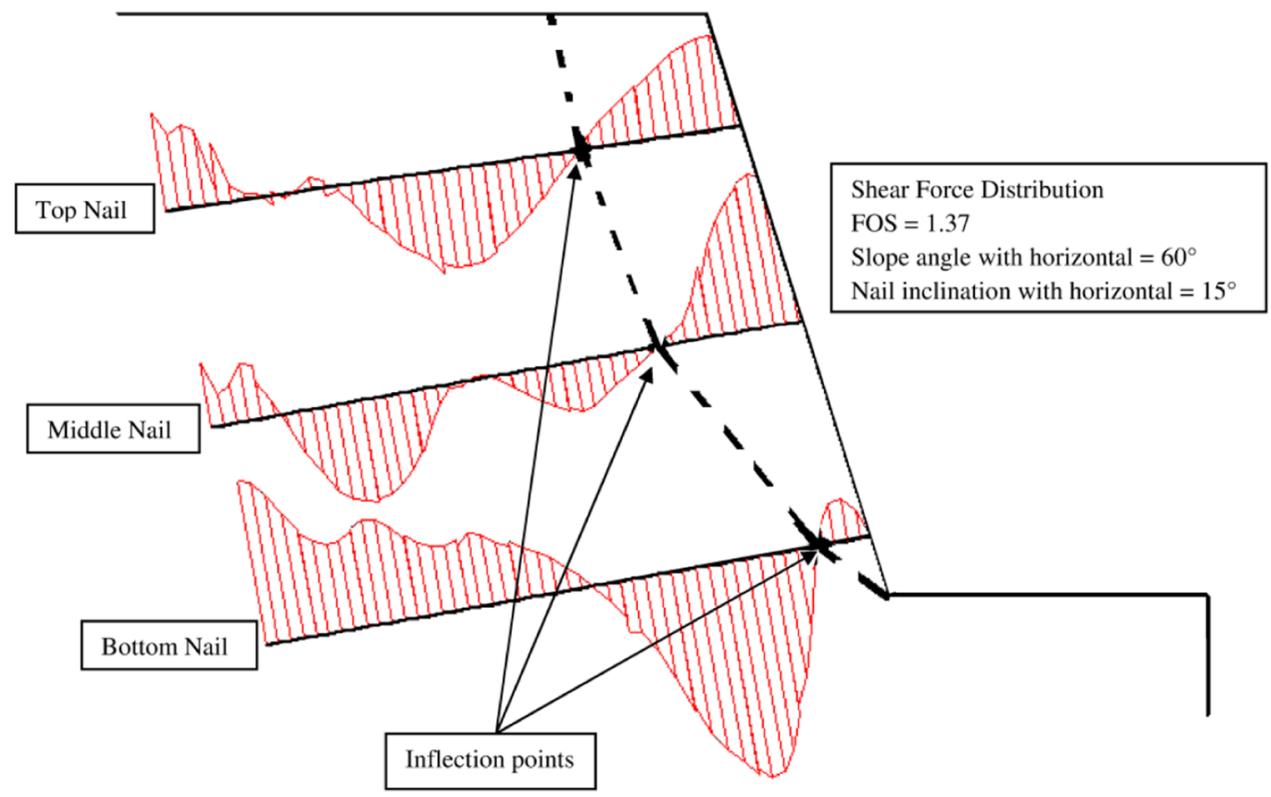

incorporate tools for boundary condition simulation whereas in PLAXIS 2D the bottom boundary is fixed in $\mathrm{x}-\mathrm{y}$ direction, left and right model boundaries are fixed in $\mathrm{x}$-direction for all cases of reinforced slopes.

(c) The model testing is effected by settlement and lateral displacement in all $\mathrm{x}, \mathrm{y}$ and $\mathrm{z}$ directions, which is not taken care of when simulated in either LE or FE analysis as both are 2D analysis codes. The slope and crest displacements observed in model testing are significantly different from LEM and FEM displacements of slope and crest, thus a variation in slip surface generation also exists.

\section{Comparison of Results from LEM and FEM}

\section{Comparison of Factor of Safety for Reinforced Slopes}

As observed from Table 6, it can be seen that limit equilibrium method calculates a higher factor of safety as compared to the finite element method. The LEM utilizes the equilibrium of forces among the slices which requires assumptions and compromises on the accuracy of the method. The FOS given by the FEM analysis is on the lower side. The FEM is based on the displacement of nodes 
Fig. 19 FOS variation with $R_{\text {inter }}$

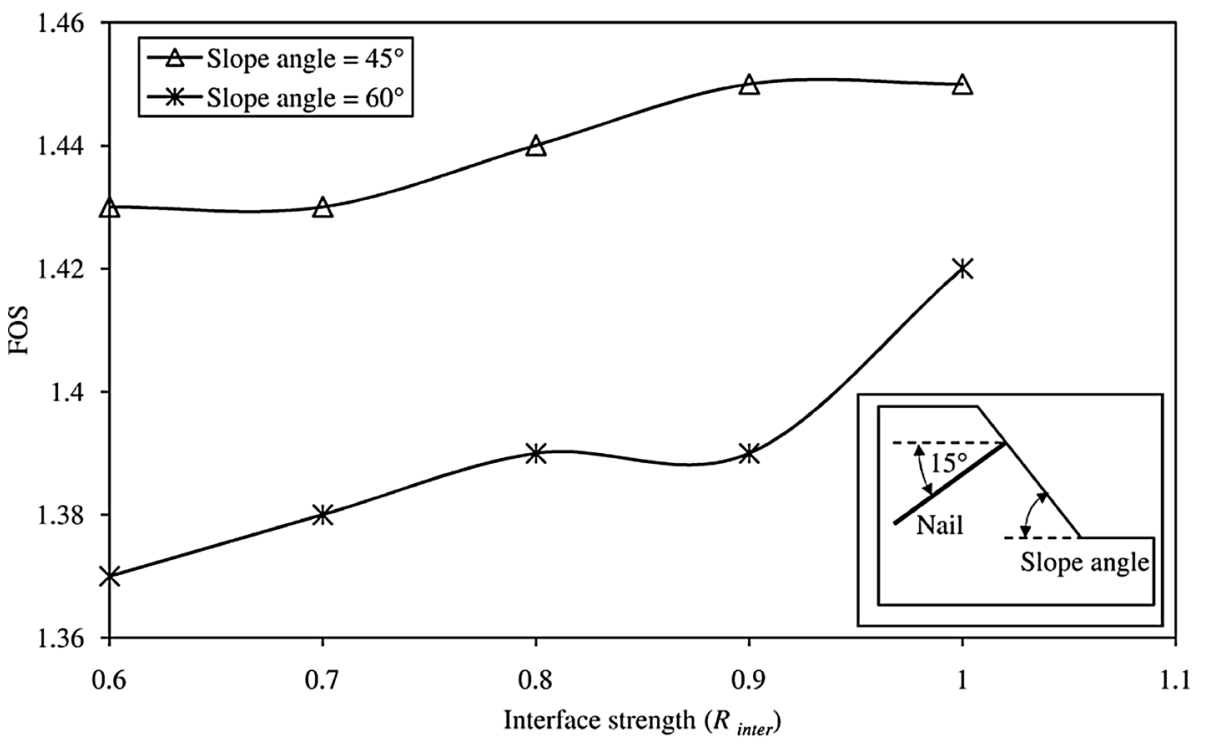

till the occurrence of slope failure. However, FOS as obtained from both the analysis show a similar pattern with the maximum FOS for nail inclination of $15^{\circ}$ in both $45^{\circ}$ and $60^{\circ}$ slope. This is followed by the FOS for $0^{\circ}$ nail inclination. The minimum FOS of safety from LEM and FEM is obtained for slope with nail inclination of $30^{\circ}$. The percentage increase in FOS with respect to FOS from FE analysis is about $24.26 \%$ with nails inclined at $0^{\circ}$ with horizontal. For $15^{\circ}$ nail inclination, LE analysis predicts $27.27 \%$ higher FOS as compared to FE analysis. For $30^{\circ}$ nail inclination, this increase is significantly small which comes out be $4.34 \%$. All the above mentioned percentage changes are for $45^{\circ}$ slope angle. In case of $60^{\circ}$ slope angle, this percentage variation in FOS between LEM and FEM ranges from 1 to $28 \%$. For nails inclination of $0^{\circ}$, a significant percentage increase of $28.20 \%$ is observed, which falls to $11.68 \%$ for $15^{\circ}$ nail inclination. An increase in FOS of just $1.85 \%$ is found with nail inclination $30^{\circ}$ from both analyses. The reasons for this higher FOS from LEM more as compared to FOS from FEM can be:

(a) LE and FE analyses have fundamental difference in the basic principles. The first is based on the limit equilibrium formulations, which are dependent on static force or moment equilibrium. As in Morgenstern-Price model used in LEM, a half-sine interslice function is used to relate the interslice normalshear forces. This in turn is used to find slice base normal force which gives the factor of safety with respect to force and moment equilibrium. The variation in FOS is obvious, since interslice weight and slice base force will depend on the shape of assumed slip surface which is circular in case of LEM. Whereas FEM is based on a stress-strain relationship, which can effectively accommodate the change in stresses. The FE analysis in PLAXIS, for example finds the slip surface, where the excessive strains are localised, and computes the FOS by strength reduction procedure for Mohr-Coulomb soil model.

(b) The FOS is primarily related to the normal stress distribution along the slip surface. A significant difference in normal stress distribution, particularly in the toe area, can be found between FE and LE analyses for a particular slip surface [44]. This difference in normal stress distribution results from the shear stress concentrations, which are not, captured in the LE analyses. In LEM, the normal forces at the base are primarily derived from the weight of the sliding mass and not the shear stress distribution which results in higher FOS prediction.

(c) In this study also, no similarity in the interslice force and critical shear surface was found between the analyses in LE and FE methods. Both analysis utilizes different shear forces and on different critical surfaces. The FE analysis computes factor of safety for each element along the slip surface, whereas a single, weighted average FOS is computed in the LE analyses. This leads to over prediction of FOS in LEM.

Moreover, Krahn [44] states, "FE analyses can handle variations in FOS without any difficulty of convergence, due to stress redistributions for change in loading conditions". However the convergence of simulations in LE is found problematic for steep slip surfaces, whereas FE overcomes such difficulties. This is why the computed FOS from the FE analysis is regarded as more reliable. 
(a)

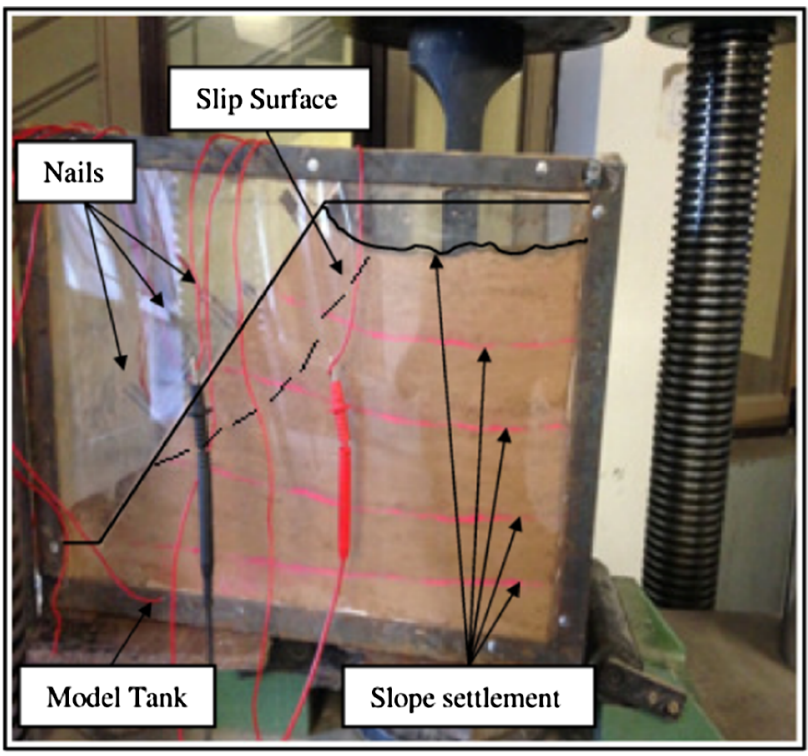

(b)

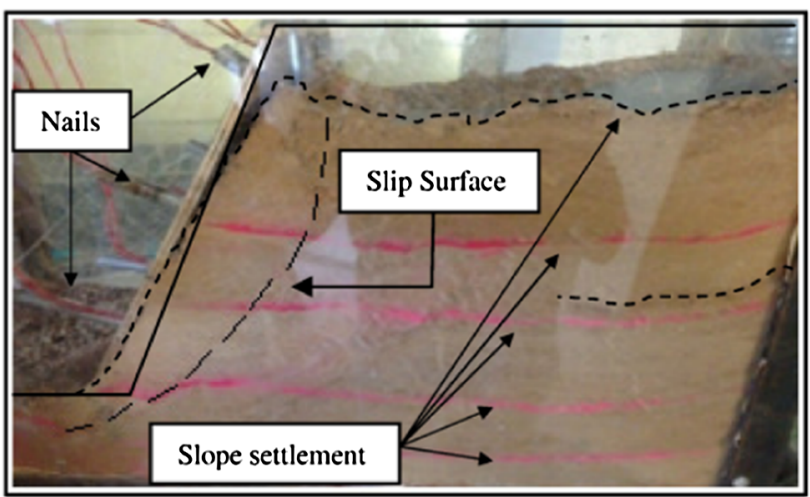

Fig. 20 a Slip surface for reinforced slope of $45^{\circ}$ by Rawat and Gupta [18]. b Slip surface for reinforced slope of $60^{\circ}$ by Rawat and Gupta [18]

Table 6 Factor of safety from LEM and FEM

\begin{tabular}{lllll}
\hline $\begin{array}{l}\text { Slope angles with } \\
\text { horizontal }\left(^{\circ}\right)\end{array}$ & \multicolumn{4}{l}{ Nail inclinations with horizontal } \\
\cline { 2 - 5 } & FOS & $0^{\circ}$ & $15^{\circ}$ & $30^{\circ}$ \\
\hline 45 & LEM & 1.69 & 1.82 & 1.20 \\
& FEM & 1.36 & 1.43 & 1.15 \\
60 & LEM & 1.50 & 1.53 & 1.10 \\
& FEM & 1.17 & 1.37 & 1.08 \\
\hline
\end{tabular}

\section{Comparison of Failure Slip Surfaces}

The slip surfaces given by LEM are circular in shape for all nail inclinations. This is due to the fact that LEM predetermines the slip surface failure as circular, linear or nonlinear. In case of FEM, the slip surfaces have a complex shape. The slip surface for nailed slopes with $45^{\circ}$ slope shows a non linear slip surface, in contrast to $60^{\circ}$ reinforced slopes with non-linear failure surfaces. The slip surfaces are also found to originate from near the slope face and terminate at the slope toe or above it. However no such failure patterns are observed from LEM analysis. The slip surfaces are found to start from the boundary of slope crest and terminate at slope toe or beyond it. No slope failure is found from LEM analysis, whereas for $60^{\circ}$ slope with $30^{\circ}$ nail inclination, the slope is found to undergo a slope slip failure as given by FEM. The variation in slip surfaces from the two approaches can be accounted for the following reasons:

(a) Different interslice shear forces and base normal forces are predicted from LEM and FEM. The LEM uses different slip circles and predicts the slip circle with minimum factor of safety as critical. The convergence of force equilibrium and moment equilibrium governs the FOS and critical slip surface. Moreover, the local factor of safety is constant throughout the analysis in LEM, thus eliminating the cases of local slip failure. On the other hand, the slip surface obtained from FEM is based on stress distribution within the continuum. The stress distribution is more realistic in FEM as local factor of safety is not constant and thus convergence of results is achieved.

(b) The line of thrust is different in both the analytical methods. The point of application of interslice normal in LE and FE is different varying from slope crest to toe. The location of thrust line depends on the slip surface geometry and loading condition. Thus, a variation in FOS and consequently in failure slip surface.

(c) The variation from deeper slip surface in LEM to shallow slip surface in FEM is due to different shear and normal stresses values generated in the respective analysis.

\section{Comparison of Nail Forces}

The nail forces obtained from limit equilibrium method and finite element method are compared for the most stable slope of $45^{\circ}$ and $60^{\circ}$ with nail inclination of $15^{\circ}$ as shown in Figs. 21 and 22. For this nail inclination in both slope angles maximum FOS is observed. As can be seen from the Fig. 21, LEM predicts higher nail forces for nail located at top and bottom of slope, whereas a smaller nail force as compared to FE analysis is found for the middle nail in $45^{\circ}$ slope. For the nail located at top, the difference in nail forces from LE and FE analysis is $35.79 \%$. A similar increase of $20.72 \%$ by LEM is observed for nail located at the bottom. This can be accounted for the fact that in LEM, 
the nails are governed by pullout capacity since no breakage of nails is observed in the top and middle nail. However, for middle nail, LEM predicts nail force which is $56.77 \%$ smaller than nail force given by FEM. This can be due to the extension of slip surface beyond the bond length in LE analysis as seen in Fig. 4b. The bond length is assumed as tensile force acting on the interslice in calculation of FOS by LEM. Thus, nail forces and FOS calculated from LE analysis depend on the length of nail considered.

For $60^{\circ}$ slope angle, the nail forces by FE analysis at top, middle and bottom are higher than those from LE analysis. A decrease of 56.16, 71.37 and $67.95 \%$ is observed for nail forces from both approaches for top, middle and bottom respectively. The reason for this change in nail forces can be the failure slip surface variations between LEM and FEM method. Moreover, the axial force distribution in FEM depicts that nails in FEM are in tension until failure, whereas LE analysis has considered compressive forces in nails at steep slope angle of $60^{\circ}$. Hence nail forces observed in LEM are found to be lower than nail forces found from FEM.

The variation in nail forces from two approaches can be due the reason that in LE analysis, soil nails are treated as concentrated loads with an assumption that only tensile forces are developed in the nails. This leads to an additional interslice shear force which reduces the destabilizing forces. The mobilized interslice shear is calculated using Eq. (4), which is based on an assumption that the shear resistance of soil and reinforcement are developed at the same rate. This leads to an over prediction of reinforcing action and correspondingly resorts to higher FOS and inaccurate nail forces. In case of analysis carried out by FEM, the nail forces depend on displacement and strain developed in soil. The displacement induces shear forces which is taken up by soil-nail interface. The distribution of this induced shear force is controlled by interaction between soil and nail. Hence soil-nail friction leads to axial tension and axial compression in nails. This difference in load transfer modeling between the two methods of analysis account for the variations in nail forces.

The variation in nail forces with inclination from two approaches can be accounted for the reason that axial forces developed in nails are found to vary with nail inclinations. LE and FE analysis method both predict the increase of nail forces with small nail inclination from $0^{\circ}$ to $15^{\circ}$ with horizontal. The nail orientation, which is the angle between the nail and normal to the shearing plane, changes with change in nail inclination. As long as nail orientation is positive nails are acting in tension which increases the shear strength of soil. The transition of nail orientation from positive to negative due to change in nail inclination
Fig. 21 Comparison of nail forces for $45^{\circ}$ slope with $15^{\circ}$ nail inclination. (Color figure online)

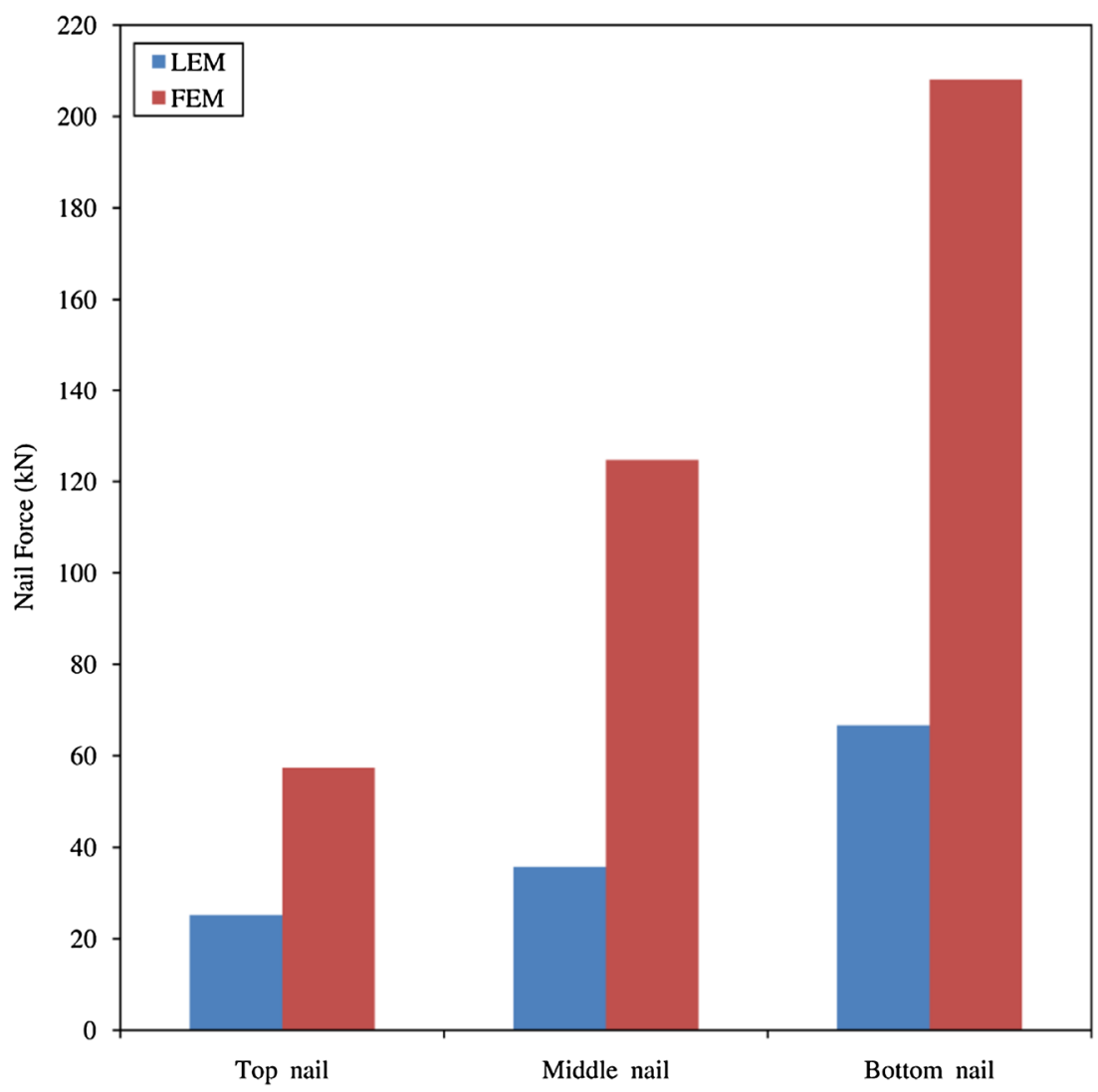


Fig. 22 Comparison of nail forces for $60^{\circ}$ slope with $15^{\circ}$ nail inclination. (Color figure online)

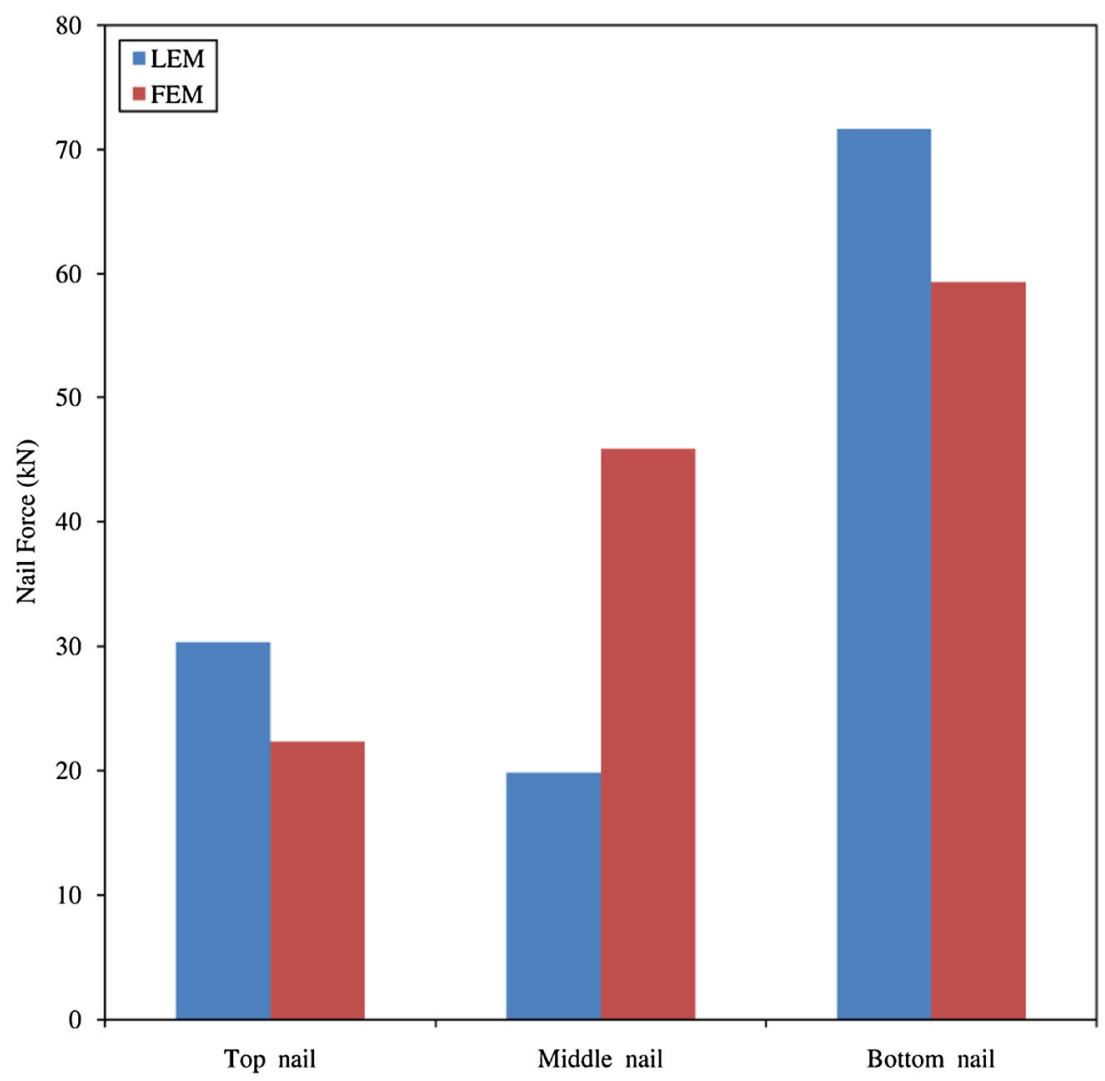

with horizontal from small $\left(0^{\circ}-15^{\circ}\right)$ to steep $\left(15^{\circ}-30^{\circ}\right)$, alters the nail behavior from tension to compression. This change reduces the reinforcing action of nails and soil strength decreases. Thus nail forces are found to increase from $0^{\circ}$ to $15^{\circ}$ and then decrease is observed between nail inclinations of $15^{\circ}$ to $30^{\circ}$. These results are consistent with analysis carried out by Mittal [45] which states "for soil nailed vertical cuts, FOS initially increases with the increase of nail inclination with horizontal (up to $15^{\circ}$ ) after which it decreases". Shiu and Chang [46] also found a similar variation in nail axial force which increased up to nail inclination of $20^{\circ}$ with horizontal and then found to become zero at nail inclination of $65^{\circ}$.

The variation in nail forces with location from two approaches can be due the reason that both LE and FE analysis observe a similar nail force variation with soil nail location. The maximum nail force is observed in bottom nails from both analyses. However, LEM predicts more nail force for bottom nail at $45^{\circ}$ than $60^{\circ}$ slope angle, whereas FE analysis suggests bottom nail in $60^{\circ}$ slope to have larger nail force as compared to nail at similar inclination and location at slope angle of $45^{\circ}$. This can be due to overburden which increases with depth. The top nail bears the overburden from slope crest which acts as surcharge for lower nails. The bottom nail is found to bear the maximum normal force and hence a larger shear force. This increase in shear force leads to mobilization of higher axial forces in bottom nails.
However, on the contrary, bottom nail force in LE analysis does not yield similar results. The results are affected by tensile strength mobilization (breakage) of nails as depicted in Fig. 5b in contrast to utilization of pullout capacity of nails as shown in Fig. 4b. Thus lower nail force for bottom nail in $60^{\circ}$ from LEM can be attributed to failure of nails during load transfer.

\section{Conclusions}

From the study carried out in this paper, the following conclusions have been derived:

(1) The limit equilibrium method predicts a higher FOS as compared to finite element method. However the most stable slope from both the analysis is found be the reinforced slope with $15^{\circ}$ nail inclination with horizontal.

(2) The FOS as obtained from LEM and FEM also signifies that the stability of slopes does not increases by increase in nail inclination. Nail inclination variation between $0^{\circ}$ and $15^{\circ}$ is found to increase the FOS of slopes which decreases as nail inclination is changed from $15^{\circ}$ to $30^{\circ}$.

(3) The slip surfaces obtained from LEM and FEM shows that as the slope angle gets steeper the failure 
surface also shows a change from circular slip surface to non-linear slip surface.

(4) The most critical slip surface from LEM is found to be at a larger distance from the slope face whereas FEM find the most critical slip surface near the slope face.

(5) The nail forces predicted from LEM have high values with variations depending on the nail location as compared to the values of nail force obtained FEM. However, both the analysis concluded maximum nail force in the bottom nail for all nail inclination.

(6) The nail forces vary with nail location. It is observed from LEM and FEM analysis that nail forces decrease from top nail to bottom nail.

(7) LEM and FEM both can predict the limiting conditions namely pullout capacity, tensile capacity or the facing capacity in the load transfer mechanism of nails. The intersection of the failure surface with nail length governs which condition has been mobilized.

(8) The results in LEM are dependent upon the nail length and bond length. Slopes having longer nail bond length are more stable than those in which no bond lengths are mobilized. On the other hand, FEM is independent of the nail length. The analysis is dependent on nail bending stiffness; axial stiffness and soil-nail interaction. Higher bending stiffness and soil-nail interaction, better is the reinforcement action of the nails and more stable the slope.

(9) FEM analysis depicts the variation in FOS with interface strength, however no provision of interface strength is available in the LEM routine. This can be another reason for the variations in results from LEM and FEM analysis.

\section{References}

1. Zhou XP, Cheng H (2013) Analysis of stability of three-dimensional slopes using the rigorous limit equilibrium method. Eng Geol 160:21-33

2. Alejano LR, Ferrero AM, Oyanguren PR, Fernández MIA (2011) Comparison of limit-equilibrium, numerical and physical models of wall slope stability. Int J Rock Mech Min Sci 48(1):16-26

3. Cheng YM, Zhu LJ (2004) Unified formulation for two dimensional slope stability analysis and limitations in factor of safety determination. Soils Found 44(6):121-127

4. Zhu DY, Lee CF, Jiang HD (2003) Generalised framework of limit equilibrium methods for slope stability analysis. Geotechnique 53(4):377-395

5. SLOPE/W (2001) A software package for slope stability analysis, Ver. 5. GEO-SLOPE International, Calgary

6. Kim J, Salgado R, Lee J (2002) Stability analysis of complex soil slopes using limit analysis. J Geotech Geoenviron Eng 128(7):546-557
7. Loukidis D, Bandini P, Salgado R (2003) Stability of seismically loaded slopes using limit analysis. Geotechnique 53(5):463-480

8. Farzaneh O, Askari F (2003) Three-dimensional analysis of nonhomogeneous slopes. J Geotech Geoenviron Eng 129(2):137-145

9. Chen Z, Wang X, Haberfield C, Yin JH, Wang Y (2001) A threedimensional slope stability analysis method using the upper bound theorem: part I: theory and methods. Int J Rock Mech Min Sci 38(3):369-378

10. Chen Z, Wang J, Wang Y, Yin JH, Haberfield C (2001) A threedimensional slope stability analysis method using the upper bound theorem: part II: numerical approaches, applications and extensions. Int J Rock Mech Min Sci 38(3):379-397

11. Lyamin AV, Sloan SW (2002) Upper bound limit analysis using linear finite elements and non-linear programming. Int $\mathrm{J}$ Numer Anal Methods Geomech 26(2):181-216

12. Griffiths DV, Lane PA (1999) Slope stability analysis by finite elements. Geotechnique 49(3):387-403

13. Brinkgreve RBJ, Engin E, Swolfs WM (2012) Plaxis 3D 2012 manual. Plaxis bv, Delft

14. Yang G, Zhong Z, Zhang Y, Fu X (2015) Optimal design of anchor cables for slope reinforcement based on stress and displacement fields. J Rock Mech Geotech Eng 7(4):411-420

15. Jeon SS (2012) Pull-out tests and slope stability analyses of nailing systems comprising single and multi rebars with grouted cement. J Central South Univ 19(1):262-272

16. Zhou WH, Yin JH, Hong CY (2011) Finite element modelling of pullout testing on a soil nail in a pullout box under different overburden and grouting pressures. Can Geotech J 48(4):557-567

17. Rabie M (2014) Comparison study between traditional and finite element methods for slopes under heavy rainfall. HBRC J 10(2):160-168

18. Rawat S, Gupta AK (2016) An Experimental and Analytical Study of Slope Stability by Soil Nailing. Electron J Geotech Eng 21(17):5577-5597

19. Jayanandan $M$ and Chandkaran S (2015). Numerical simulation of soil nailed structures International Journal of Engineering Research \& Technology (IJERT), ISSN: 2278-0181,Vol.4 Issue 8

20. Cheuk CY, Ho KKS, Lam AYT (2013) Influence of soil nail orientations on stabilizing mechanisms of loose fill slopes. Can Geotech J 50(12):1236-1249

21. Cheuk CY, Ng CWW, Sun HW (2005) Numerical experiments of soil nails in loose fill slopes subjected to rainfall infiltration effects. Comput Geotech 32(4):290-303

22. Murthy BRS, Babu GLS, Srinivas A (2002) Analysis of prototype soil nailed retaining wall. Gr Improvement 6(3):129-136

23. Babu GLS, Murthy BRS, Srinivas A (2002) Analysis of construction factors influencing the behaviour of soil-nailed earth retaining walls. Proc Inst Civ Eng-Gr Improvement 6(3):137-143

24. Wei W (2008) Three dimensional slope stability analysis and failure mechanism. Doctoral dissertation, The Hong Kong Polytechnic University, Hong Kong

25. Zheng YR, Zhao SY, Song YK (2005) Advance of study on the strength reduction finite element method $[\mathrm{J}]$. J Logist Eng Univ $3: 1-6$

26. Shukha R, Baker R (2008) Design implications of the vertical pseudo-static coefficient in slope analysis. Comput Geotech 35:86-96

27. Gurocak Z, Alemdag S, Zaman MM (2008) Rock slope stability and excavatability assessment of rocks at the Kapikaya dam site, Turkey. Eng Geol 96:17-27

28. Hao J, Wang B (2014) Parameter sensitivity analysis on deformation of composite soil-nailed wall using artificial neural networks and orthogonal experiment. Math Probl Eng. doi:10.1155/ 2013/502362 
29. Pei HF, Li C, Zhu HH, Wang YJ (2013) Slope stability analysis based on measured strains along soil nails using FBG sensing technology. Math Probl Eng. doi:10.1155/2013/561360

30. Esmaeili F, Varshosaz M, Ebadi H (2013) Displacement measurement of the soil nail walls by using close range photogrammetry and introduction of CPDA method. Measurement 46(9):3449-3459

31. Lin P, Bathurst RJ, Javankhoshdel S, Liu J (2016) Statistical analysis of the effective stress method and modifications for prediction of ultimate bond strength of soil nails. Acta Geotechnica. doi:10.1007/s11440-016-0477-1

32. Li N, Cheng YM (2014) Laboratory and 3-D-distinct element analysis of failure mechanism of slope under external surcharge. Nat Hazards Earth Syst Sci Discuss 2:5937-5970

33. Spencer E (1967) A method of analysis of the stability of embankments assuming parallel inter-slice forces. Geotechnique 17(1):11-26

34. Morgenstern NR, Price VE (1965) The analysis of the stability of general slip surfaces. Geotechnique 15(1):79-93

35. Wright SG, Duncan JM (1991) Limit equilibrium stability analyses for reinforced slopes. Transp Res Rec 1330:40-46

36. Rawat S, Zodinpuii R, Manna B, Sharma KG (2014) Investigation on failure mechanism of nailed soil slopes under surcharge loading: testing and analysis. Geomech Geoeng 9(1):18-35

37. Griffiths DV, Smith IM, Molenkamp F (1982). Computer implementation of a double-hardening model for sand. In Proc.
IUTAM conf. on deformation and failure of granular materials. Delft, pp 213-221

38. Fawaz A, Farah E, Hagechehade F (2014) Slope stability analysis using numerical modelling. Am J Civ Eng 2(3):60-67

39. Lin H, Xiong W, Cao P (2013) Stability of soil nailed slope using strength reduction method. Eur J Environ Civ Eng 17(9):872-885

40. FHWA (2003). Geotechnical engineering circular No 7-soil nail walls. Report FHWA0-IF-03-017. US Department of Transportation, Federal Highway Administration, Washington, DC.

41. Shiu YK, Chang GWK (2006) Effects of inclination, length pattern and bending stiffness of soil nails on behavior of nailed structures. GEO Report No.197. Geotechnical Engineering Office, Hong Kong.

42. Fan CC, Luo JH (2008) Numerical study on the optimum layout of soil nailed slopes. Comput Geotech 35(4):585-599

43. Babu GS, Singh VP (2009) Simulation of soil nail structures using PLAXIS 2D. Plaxis Bulletin, (Spring Issue No. 25), pp 16-21

44. Krahn J (2004) Stability modeling with SLOPE/W: An engineering methodology. The 11th Edt. Canada

45. Mittal S, Biswas AK (2006) River bank erosion control by soil nailing. Geotech Geol Eng 24(6):1821-1833

46. Shiu YK, Chang GWK (2006) Effects of inclination, length pattern and bending stiffness of soil nails on behaviour of nailed structures. Geotechnical Engineering Office, Civil Engineering and Development Department, Hong Kong 